\title{
Supplementation of linoleic acid (C18:2n-6) or $\alpha$-linolenic acid (C18:3n-3) changes microbial agonist-induced oxylipid biosynthesis
}

\author{
V. E. Ryman, ${ }^{*}$ N. Packiriswamy, ${ }^{*}$ B. Norby, ${ }^{*}$ S. E. Schmidt, † A. L. Lock, † and L. M. Sordillo*1 \\ *Department of Large Animal Clinical Sciences, College of Veterinary Medicine, and \\ †Department of Animal Science, Michigan State University, East Lansing 48824
}

\begin{abstract}
Oxylipids are derived from polyunsaturated fatty acids (PUFA) in cellular membranes and the relative abundance or balance may contribute to disease pathogenesis. Previous studies documented unique oxylipid profiles from cows with either coliform or Streptococcus uberis mastitis, suggesting that lipid mediator biosynthesis may be dependent on the type of microbialderived agonist. Changing the fatty acid content of peripheral blood leukocytes also may be critical to the relative expression of oxylipid profiles and the outcome of bacterial infection. No information is available in dairy cows describing how changing cellular PUFA content will modify oxylipids in the context of a microbial agonist challenge. Therefore, the hypothesis for the current study was that PUFA supplementation would change bovine leukocyte fatty acid content and respective oxylipid profiles from ex vivo microbial agonistchallenged leukocytes. Fatty acid content of leukocytes and plasma was quantified in (1) samples from cows not supplemented with PUFA, (2) cows supplemented with linoleic acid (LnA), and (3) cows supplemented with $\alpha$-linolenic acid (ALA). Plasma oxylipids were assessed after $S$. uberis or lipopolysaccharide exposure and was compared with unstimulated oxylipid profiles. Fatty acid supplementation with ALA significantly increased ALA content of blood leukocytes and plasma relative to LnA. Fatty acid supplementation affected several S. uberis-induced oxylipids, but only S. uberisinduced 15-oxoETE was greater with ALA supplementation compared with LnA. Notably, only LPS-induced 5,6 $\mathrm{LXA}_{4}$ was altered with fatty acid supplementation, but no significant effect of LnA vs. ALA treatment was identified. Future studies are needed to understand how leukocyte activation and membrane PUFA availability collectively contribute to differential oxylipid profiles.
\end{abstract}

Received June 13, 2016.

Accepted November 18, 2016.

${ }^{1}$ Corresponding author: sordillo@msu.edu
Key words: oxylipin, lipid mediator, polyunsaturated fatty acid, Streptococcus uberis, lipopolysaccharide

\section{INTRODUCTION}

The outcome of bovine mastitis may be dependent, in part, on potent lipid mediators derived from PUFA. Specifically, the oxygenation of PUFA following cleavage from the phospholipid membrane generates a profile of pro- and anti-inflammatory oxylipids. The profile of pro- and anti-inflammatory oxylipids may depend on the specific causative pathogen and its capability to induce different immune recognition and signaling pathways (Bannerman et al., 2004a; Mavangira et al., 2015; Ryman et al., 2015). For example, a diverse oxylipid profile was robustly upregulated in milk during severe gram-negative coliform mastitis, whereas oxylipid profiles were not changed in milk during clinical grampositive Streptococcus uberis mastitis (Mavangira et al., 2015; Ryman et al., 2015). Coliform mastitis is characterized by an acute, robust inflammatory response with clinical symptoms appearing in as little as $8 \mathrm{~h}$ after challenge predominantly as a result of LPS exposure (Eberhart, 1977; Bannerman et al., 2004b; Moyes et al., 2014). In contrast, the uncontrolled inflammatory response to $S$. uberis does not result in clinical symptoms until several days after infection and may develop into a chronic inflammatory disease (Thomas et al., 1994; Pedersen et al., 2003). Thus, understanding oxylipid biosynthesis in the context of different microbial agonist challenges may be critical for developing optimal nutritional and pharmacological strategies to manage disease prevalence and severity.

Several PUFA, including linoleic acid $(\operatorname{LnA}$, C18:2n-6), arachidonic acid (ArA, C20:4n-6), eicosapentaenoic acid (EPA, C20:5n-3), and docosahexaenoic acid (DHA, C22:6n-3), are the predominant substrates for oxylipid biosynthesis (Raphael and Sordillo, 2013). The PUFA are esterified to the phospholipid membrane and are cleaved by calcium-dependent cytosolic phospholipase $\mathrm{A}_{2}$ in response to a variety of agonists, such as recognition of pathogen-associated molecular 
patterns by host pathogen receptors (Buczynski et al., 2009; Chiang et al., 2012). Enzymatic and nonenzymatic pathways oxidize cleaved PUFA to create a complex network of oxylipids (Buczynski et al., 2009). Enzymatic oxidation pathways include the cyclooxygenase, lipoxygenase (LOX), and cytochrome P450 (CYP) pathways. Nonenzymatic oxidation is mediated by reactive oxygen species and free radicals. Initial peroxidation products including hydroperoxyoctadecadienoic acids are immediately reduced to stable hydroxyl analogs, such as hydroxyeicosatetraenoic acids (HETE; Sordillo et al., 2005; Serhan and Petasis, 2011; Smith et al., 2011). Reduced oxylipids, including hydroxyls and epoxides, can serve as substrates for metabolism to dehydrogenase (e.g., oxoeicosatetraenoic acids, oxoETE) and hydrolase products (e.g., dihydroxyeicosapentaenoic acid, DiHETE; Ramsden et al., 2012). The effects of oxylipids on inflammation may depend on method of oxidation and the degree of metabolism. For example, 15-LOX-derived lipoxin $\mathrm{A}_{4}\left(\mathbf{L X \mathbf { A } _ { 4 } )}\right.$ prevented disruption of the rat small bowel mesenteric endothelial barrier during LPS challenge (Ereso et al., 2009). However, the precursor to $\mathrm{LXA}_{4}, 15$-hydroperoxyeicosatetraenoic acid, induced apoptosis of bovine aortic endothelial cells in an oxidative stress model (Sordillo et al., 2005).

In addition to the method of oxidation and degree of metabolism, the availability of PUFA substrate can directly alter oxylipid profiles. Linoleic acid and $\alpha$-linolenic acid (ALA, C18:3n-3) are essential fatty acids that must be provided in the diet because de novo synthesis requires desaturase enzymes that are absent in mammals (Nakamura and Nara, 2003). Dietary LnA contributes to lipid membrane LnA content but also can be used for de novo ArA synthesis. Similarly, ALA can be used for EPA and DHA de novo synthesis. The de novo synthesis requires a series of desaturation, elongation, and potentially $\beta$-oxidation events (Marcel et al., 1968; Sinclair et al., 2002). In monogastrics, feeding essential fatty acids or other PUFA changed the fatty acid profile of plasma and various tissues (Ramsden et al., 2012). Similarly, previous research in monogastrics and ruminants showed that abundance and type of PUFA within the phospholipid membrane can be altered by the diet and influence disease status (Calder, 2008; Raphael and Sordillo, 2013; Min et al., 2014). For example, obese pregnant women supplemented with $1,200 \mathrm{mg}$ of EPA and $800 \mathrm{mg}$ of DHA resulted in decreased systemic markers of inflammation, such as C-reactive protein and pro-inflammatory cytokines (Haghiac et al., 2015). One of the ways in which PUFA supplementation is thought to mediate disease severity is through the biosynthesis of oxylipids. Supplementation of humans with $1,008 \mathrm{mg}$ of EPA and $672 \mathrm{mg}$ of DHA contributed to greater EPA-derived, but not
DHA-derived, oxylipids (Schuchardt et al., 2014). Conversely, reducing nutritional $\mathrm{LnA}$ in humans decreased LnA-derived plasma oxylipids (Ramsden et al., 2012). In dairy cows, dietary PUFA supplementation is more challenging because isomerization and biohydrogenation of PUFA by rumen microbes results in conversion of PUFA to SFA (Glasser et al., 2008; Jenkins et al., 2008). Recent studies used abomasal supplementation of PUFA to modify milk fat, but PUFA content of cells and tissues was not investigated, so it is unclear if abomasal supplementation changes cellular PUFA content as well as if there is any effect on oxylipids during inflammation (Lock et al., 2007). Thus, the hypothesis for the current study was that PUFA supplementation would change bovine leukocyte fatty acid content and respective oxylipid profiles from ex vivo microbial agonist-challenged leukocytes.

\section{MATERIALS AND METHODS}

\section{Supplementation of Fatty Acids by Abomasal Infusion}

All experimental procedures were approved by the Institutional Animal Care and Use Committee at Michigan State University. Six ruminally fistulated multiparous $(2+)$ mid-lactation Holstein cows (91.7 $\pm 8.36 \mathrm{~d}$ in milk) from the Michigan State University Dairy Teaching and Research Center (East Lansing, MI) were blocked by milk yield. The cows were then randomly assigned to a treatment sequence in a replicated $3 \times 3$ Latin square design experiment with a 7-d preliminary period and three 7-d treatment periods separated by 7-d washout periods (Lock et al., 2007). Prior to the first treatment period, all cows were fitted with an abomasal infusion line. All lines were flushed daily with water and ethanol during the treatment periods to ensure proper delivery of the fatty acid infusion treatments into the abomasum. Treatments consisted of an ethanol carrier infusion ( CON), LnA infusion, and ALA infusion. The LnA infusion blend consisted of $82 \%$ safflower oil, $17 \%$ high omega flax oil, and $1 \%$ palm oil. The ALA infusion blend consisted of $93 \%$ high omega flax oil, $6 \%$ palm oil, and $2 \%$ safflower oil. Fat blends were dissolved in ethanol before infusion and administered at a dose of approximately $62 \mathrm{~g} / \mathrm{d}$ with LnA or ALA comprising approximately $40 \mathrm{~g} / \mathrm{d}$. The fatty acid profile of infusion treatments displayed in Table 1 were determined by GLC according to methods previously described (Lock et al., 2013). Daily infusions were divided and administered at 6 -h intervals throughout each 7-d treatment period. The infusions were administered at $0500,1100,1700$, and $2300 \mathrm{~h}$. Blood was collected in $4 \mathrm{~m} M$ EDTA anticoagulant prior 
Table 1. Fatty acid composition of linoleic acid $(\operatorname{LnA})$ and $\alpha$-linolenic acid (ALA) infusions

\begin{tabular}{|c|c|c|}
\hline Fatty acid & $\begin{array}{c}\operatorname{LnA} \\
(\mathrm{g} / 100 \mathrm{~g})\end{array}$ & $\underset{(\mathrm{g} / 100 \mathrm{~g})}{\mathrm{ALA}}$ \\
\hline Myristic acid (C14:0) & 0.09 & 0.09 \\
\hline Palmitic acid (C16:0) & 6.40 & 6.36 \\
\hline Palmitoleic acid (C16:1 cis-9) & 0.17 & 0.05 \\
\hline Stearic acid (C18:0) & 2.44 & 2.52 \\
\hline Oleic acid (C18:1 cis-9) & 16.05 & 15.22 \\
\hline $\operatorname{LnA}(\mathrm{C} 18: 2 \mathrm{n}-6)$ & 60.92 & 13.41 \\
\hline ALA (C18:3n-3) & 10.68 & 60.49 \\
\hline$\Sigma \mathrm{SFA}$ & 1.62 & 1.42 \\
\hline$\Sigma$ MUFA & 9.63 & 9.43 \\
\hline$\Sigma$ PUFA & 17.05 & 16.06 \\
\hline$\Sigma$ n-3 PUFA & 71.65 & 74.07 \\
\hline$\Sigma \mathrm{n}-6$ PUFA & 10.70 & 60.62 \\
\hline
\end{tabular}

to treatment, after a 7-d washout period (prior to next treatment), and $7 \mathrm{~d}$ after treatment with PUFA. Blood samples were transported back to the laboratory on ice for immediate collection to quantify fatty acid content of blood leukocytes or for ex vivo challenge with microbial agonists. Ex vivo challenge with microbial agonists is described in the next section.

Cows were housed individually in tie stalls throughout the experiment. The cows were milked twice daily at 0330 and $1630 \mathrm{~h}$. The SCC was monitored before the beginning of the trial and was an average of 177,667 $\mathrm{SCC} / \mathrm{mL}$. Enrolled cows were monitored for symptoms of mastitis and other diseases. Abnormalities in milk and mammary gland appearance were assessed for detection of clinical mastitis. Mammary gland abnormalities included pain, swelling, or hardening of the mammary gland, heat, or redness, and milk abnormalities included a watery consistency, clots, or pus. Access to feed was blocked from 0800 to 1000 h daily to allow for collection of orts and distribution of feed. Feed intake was measured daily and cows were fed at $115 \%$ of expected DMI at $1000 \mathrm{~h}$ each day. Water was available ad libitum at all times. Stalls were bedded with sawdust and cleaned twice daily. The composition of the diet was a standard TMR with mineral and vitamin supplementation (Table 2). The DM content of the forages was determined twice weekly and the diets were adjusted as needed.

\section{Microbial Agonist Ex Vivo Challenge of Blood Leukocytes from Nonsupplemented and Supplemented Animals}

Heat-killed S. uberis strain 0140J was prepared by collecting 3 pure $S$. uberis colonies from a blood agar plate and adding them to $100 \mathrm{~mL}$ of RPMI 1640 medium (Cellgro, Manassas, VA) containing 5\% fetal bovine serum, $300 \mathrm{mg} / \mathrm{mL}$ of L-glutamine, and $0.1 \mu M$ selenium. The bacterial suspension was shaken at $37^{\circ} \mathrm{C}$ for $13 \mathrm{~h}$. After that time, the suspension was heat-killed in a $65^{\circ} \mathrm{C}$ water bath for $45 \mathrm{~min}$. Suspensions diluted in $1 \times$ PBS were aliquoted at $10^{9}$ cfu of S. uberis/ $\mathrm{mL}$ and frozen at $-20^{\circ} \mathrm{C}$ until use. Ultrapure LPS derived from Escherichia coli (InvivoGen, San Diego, $\mathrm{CA}$ ) was purchased at a stock of $5 \mathrm{mg} / \mathrm{mL}$ and kept at $-20^{\circ} \mathrm{C}$ until use, at which time LPS was diluted in $1 \times$ PBS to $1 \mu \mathrm{g} / \mathrm{mL}$ before experimental agonist challenge. Blood samples from cows abomasally infused with ethanol carrier, LnA, or ALA were aliquoted into pre-labeled tubes and either $10^{7} \mathrm{cfu}$ of $S$. uberis $/ \mathrm{mL}, 1$ $\mu \mathrm{g} / \mathrm{mL}$ of LPS, or $1 \times$ PBS were added. The dose of LPS was chosen based on previous literature (Sellers et al., 2013). The dose of S. uberis was chosen based on previous research demonstrating that pathogen load following $S$. uberis intramammary challenge may reach up to $10^{7} / \mathrm{mL}$ (Leigh et al., 2010). All samples, including unstimulated $1 \times$ PBS control, were gently rotated for mixing then incubated in a $37^{\circ} \mathrm{C}$ water bath for 4 $\mathrm{h}$. The 4-h time point was selected based on previous studies with whole blood LPS challenge (Røntved et al., 2005) and replicated with heat-killed S. uberis so as to compare differences in fatty acid and oxylipid profiles at a similar time point.

\section{Whole Blood Processing for Quantification of Fatty Acids and Oxylipids}

Whole blood collected from animals in the 3 treatment groups (CON, LnA, and ALA), but not cultured

Table 2. Ingredient and nutrient composition of the treatment diet ${ }^{1}$

\begin{tabular}{lc}
\hline Item & Value \\
\hline Ingredient (\% of DM) & \\
Corn silage & 28.4 \\
Alfalfa silage & 16.7 \\
Wheat straw & 3.2 \\
Dry ground corn & 17.5 \\
High moisture corn & 8.5 \\
Soybean meal & 14.8 \\
Cottonseed with lint & 7.4 \\
Vitamin-mineral mix & \\
Limestone & 2.1 \\
Sodium bicarbonate & 0.76 \\
Nutrient composition (\% of DM) & 0.75 \\
DM (\%) & \\
NDF & 58.7 \\
CP & 30.6 \\
Starch & 17.5 \\
Fatty acid & 26.3 \\
\hline
\end{tabular}

${ }^{1}$ Vitamin and mineral mix contained $34.1 \%$ dry ground shell corn, $25.6 \%$ white salt, $21.8 \%$ calcium carbonate, $9.1 \%$ Biofos (Mosaic Crop Nutrition, Riverview, FL), $3.9 \%$ magnesium oxide, $2 \%$ soybean oil, and $<1 \%$ of each of the following: manganese sulfate, zinc sulfate, ferrous sulfate, copper sulfate, iodine, cobalt carbonate, vitamin E, vitamin A, vitamin $\mathrm{D}$, and selenium. 
with microbial agonists, was collected and immediately spun at $4,816 \times g$ for $20 \mathrm{~min}$ at room temperature to enable separation of buffy coat. The buffy coat fraction, containing primarily monocytes, neutrophils, and lymphocytes, was collected and deposited into a separate 50-mL tube. A volume of $20 \mathrm{~mL}$ of AmmoniumChloride-Potassium lysing buffer (Qiagen, Hamburg, Germany) was added and incubated for 4 min at room temperature to remove contaminating erythrocytes. To neutralize excess lysis buffer, $20 \mathrm{~mL}$ of $1 \times$ PBS was added after incubation. The samples were spun at 4,816 $\times g$ for $5 \mathrm{~min}$ at $4^{\circ} \mathrm{C}$ and the supernatant containing lysed erythrocyte fractions was discarded. The pellet was resuspended in $20 \mathrm{~mL}$ of $1 \times$ PBS and washed twice. Last, the supernatant was discarded and the leukocyte pellet was stored at $-80^{\circ} \mathrm{C}$ until further analysis.

Whole blood collected from animals in the 3 treatment groups (CON, LnA, and ALA), then cultured with microbial agonists (LPS and heat-killed S. uberis) for $4 \mathrm{~h}$, was centrifuged at $4,816 \times g$ for $20 \mathrm{~min}$ at room temperature. A control sample, not stimulated with microbial agonists, was simultaneously incubated at $4 \mathrm{~h}$, then centrifuged at $4,816 \times g$ for $20 \mathrm{~min}$ at room temperature. A 2-mL aliquot of plasma then was collected and immediately flash-frozen in liquid nitrogen until solid phase extraction.

\section{Chemicals and Reagents}

Liquid chromatography/mass spectrometry (LCMS) grade acetonitrile, LC-MS methanol, formic acid, EDTA, and triphenylphosphine (TPP) were purchased from Sigma-Aldrich (St. Louis, MO). Standards, deuterated and nondeuterated, and indomethacin were purchased from Cayman Chemical (Ann Arbor, MI). Butylated hydroxy toluene (BHT) was purchased from ACROS (Morris Plains, NJ).

\section{Solid Phase Extraction of Fatty Acids and Oxylipids in Leukocyte and Cultured Plasma}

The leukocyte pellets were thawed on ice and resuspended in $600 \mu \mathrm{L}$ of PBS. A $40-\mu \mathrm{L}$ aliquot was collected for quantification of total DNA in each sample to normalize fatty acid levels (Silva et al., 2013; Mattmiller et al., 2014). Total DNA was quantified using Broad Range Quant-iT DNA Assay kit (Life Technologies, Carlsbad, CA) according to the manufacturer's instructions. Samples were sonicated after addition of $15 \mu \mathrm{L}$ of internal standards and $4 \mu \mathrm{L}$ of antioxidant reducing agent. The antioxidant reducing agent mixture was 0.9 $\mathrm{m} M$ of BHT, $0.54 \mathrm{~m} M$ EDTA, $3.2 \mathrm{~m} M$ TPP, and 5.6 $\mathrm{m} M$ indomethacin in 50\% methanol, $25 \%$ ethanol, and
$25 \%$ water. Samples were immediately frozen in liquid nitrogen and stored at $-80^{\circ} \mathrm{C}$. The internal standard mixture contained $0.25 \mu M$ 5(S)-HETE_ $d_{8}, 0.25 \mu M$ 15(S)-HETE_d $d_{8}, 0.5 \mu M$ 8(9)-epoxyeicosatrienoic acid $(\mathbf{E E T}) \_d_{11}, 0.5 \mu M$ prostaglandin E2_ $d_{9}, 0.25 \mu M$ 8,9-dihydroxyeicosatrienoic acid (DHET) $d_{11}, 50 \mu M$ AA_ $d_{8}, 2 \mu M$ 2-arachidonoyl glycerol_ $d_{8}$, and $0.2 \mu M$ arachidonoyl ethanolamide_d $d_{8}$. A volume of $900 \mu \mathrm{L}$ of methanol was added to each sample. To release fatty acids from cell membranes, samples were hydrolyzed with $3 \mathrm{~m} M$ potassium hydroxide and incubated at $45^{\circ} \mathrm{C}$ for $45 \mathrm{~min}$. Samples were cooled, acidified to a $\mathrm{pH}<3$ using $1 \mathrm{~N}$ hydrochloric acid, and centrifuged at 4,816 $\times g$ for $45 \mathrm{~min}$ at $4^{\circ} \mathrm{C}$. Supernatants were collected for solid phase extraction.

For flash-frozen plasma collected from blood following $4 \mathrm{~h}$ of microbial agonist challenge, all plasma aliquots were thawed on ice. A volume of $4 \mu \mathrm{L}$ of antioxidant reducing agent, $15 \mu \mathrm{L}$ of internal standards, and $2 \mu \mathrm{L}$ of formic acid was added. The antioxidant reducing agent contained $0.9 \mathrm{~m} M$ of BHT, $0.54 \mathrm{~m} M$ EDTA, $3.2 \mathrm{~m} M$ TPP, and $5.6 \mathrm{~m} M$ indomethacin in $50 \%$ methanol, $25 \%$ ethanol, and $25 \%$ water. Internal standards in ethanol were $0.25 \mu M 5(\mathrm{~S})$-HETE_ $d_{8}, 0.25 \mu M$ 15(S)-HETE_d $d_{8}, 0.5 \mu M$ EET_d $d_{11}, 0.5 \mu M$ prostaglandin E2_d, $0.25 \mu M$ DHET_d $d_{11}, 50 \mu M$ AA_d $d_{8}, 2 \mu M$ 2 - arachidonoyl glycerol_ $d_{8}$, and $0.2 \mu M$ arachidonoyl ethanolamide_ $d_{8}$. A volume of $5 \mathrm{~mL}$ of methanol was added and the sample was vigorously vortexed for 2 min. Samples were incubated for $15 \mathrm{~min}$ at room temperature and then centrifuged at $14,000 \times g$ for 10 min at $4^{\circ} \mathrm{C}$. The supernatant was aspirated and added to $95 \mathrm{~mL}$ of HPLC-grade water and $95 \mu \mathrm{L}$ of formic acid. Solid phase extraction was conducted with Oasis HLB 12cc (500 mg) LP Extraction Columns (Waters, Milford, MA) pre-conditioned with $6 \mathrm{~mL}$ of methanol followed by $6 \mathrm{~mL}$ of HPLC water. Sample extracts from plasma and blood leukocytes were loaded onto the columns and then washed with $6 \mathrm{~mL}$ of $20 \%$ methanol. Columns were dried under full vacuum for $4 \mathrm{~min}$ and extracts were eluted with $6 \mathrm{~mL}$ of methanol:acetonitrile 50:50 (vol:vol). Solvents were removed under vacuum using a Savant SpeedVac. Oxylipid extracts were reconstituted in $150 \mu \mathrm{L}$ of methanol:water $(2: 1)$ and centrifuged at $14,000 \times g$ for $15 \mathrm{~min}$ at $4^{\circ} \mathrm{C}$. The supernatant was transferred to a chromatography vial, topped with argon, and stored at $-20^{\circ} \mathrm{C}$ until analysis.

\section{LC-MS Quantification of Fatty Acids}

All fatty acids, both leukocyte-derived and plasmaderived, were quantified based on previously described techniques (Ryman et al., 2015). Briefly, reverse-phase 
LC on a Waters Acquity ultra performance LC BEH C18 $1.7 \mu M$ column $(2.1 \times 100 \mathrm{~mm})$ was used at a flow rate of $0.6 \mathrm{~mL} / \mathrm{min}$ at $35^{\circ} \mathrm{C}$. The quadropole MS was in electrospray negative ionization mode and voltage was $-3 \mathrm{kV}$ with the turbo ion spray source temperature at $450^{\circ} \mathrm{C}$. The isocratic mobile phase for method 1 was acetonitrile:water:formic acid (45:55:0.01 vol/vol/vol) and 15 min of analysis time. Method 2 had an isocratic mobile phase consisting of acetonitrile:methanol:wate r:formic acid (47.4:15.8:26.8:0.01 vol/vol/vol/vol) and 10 min of analysis time. A total of 5 PUFA, 2 SFA, and 1 MUFA were quantified by matching mass- 1 and retention time with corresponding deuterated internal standard abundance and calibrated to a linear 5-point standard curve $\left(\mathrm{R}^{2}>0.99\right)$. Fatty acids quantified by Waters Empower Z software (Waters) for plasma samples and hydrolyzed leukocytes were as follows: LnA, ALA, ArA, EPA, DHA, palmitic acid, oleic acid, and stearic acid. The limit of detection was established as the lowest point of each standard curve.

\section{LC-MS/MS Quantification of Oxylipids}

Plasma oxylipids were quantified based on techniques previously described (Mavangira et al., 2015). Briefly, a Waters Acquity UPLC coupled to a Waters Xevo TQ-S triple quadrupole mass spectrometer (Waters) was employed. Mobile phase A was HPLC water with $0.1 \%$ formic acid, and mobile phase $\mathrm{B}$ was acetonitrile. Flow rate across the C18 HPLC column was $0.3 \mathrm{~mL} /$ min. Linear gradient steps were programmed in the following manner (A/B ratio): time 0 to $0.5 \mathrm{~min}(99 / 1)$, to $(60 / 40)$ at $2.0 \mathrm{~min}$, to $(20 / 80)$ at $8.0 \mathrm{~min}$, to $(1 / 99)$ at $9.0 \mathrm{~min}, 0.5 \mathrm{~min}$, held at (1/99) until min 13.0, then return to $(99 / 1)$ at $13.01 \mathrm{~min}$, and held at this condition until $15.0 \mathrm{~min}$. Oxylipids were detected using electrospray ionization in negative-ion mode. Cone voltages and collision voltages were optimized using the Waters QuanOptimize software (Mavangira et al., 2015).

\section{Statistical Analysis}

Statistical analyses were performed using commercially available software (SAS 9.3, SAS Institute Inc., Cary, NC). The efficacy of abomasal supplementation treatment groups on absolute fatty acid content of leukocyte and plasma without ex vivo microbial agonist challenge or in the context of microbial agonist challenge was analyzed as a balanced, 2 -square, $3 \times 3$ Latin square design, including treatment and period as fixed effects. Delta values for changes in microbial agonistinduced fatty acid and oxylipid concentrations relative to abomasal supplementation were tested with the same model. Delta values for microbial agonist-induced fatty acid and oxylipid concentrations were calculated by subtracting the concentration of fatty acids or oxylipids detected in unstimulated samples from concentrations in challenged samples. Parameterization of the model was $y_{i j k}=\mu+\alpha_{i}+\beta_{j}+e_{i j k}$, where $y_{i j k}$ was the observation at treatment $i$ and period $j$ on the $k$ th cow, $\mu$ is the overall mean, $\alpha_{i}$ is the effect of the $i$ th treatment $(i=1,2,3), \beta_{j}$ was the effect of the $j$ th period $(j$ $=1,2,3), e_{i j k}$ is the random residual effect for all $i, j$, $k$, and $e_{i j k}$ is supposed normally, independently identically distributed $\operatorname{NIID}\left(0, \sigma_{e}^{2}\right)$, with a mean of 0 and a variance $\sigma_{e}$. The compound symmetry covariance structure was used to model the repeated measurement of cows in different periods, and Kenward-Roger adjustment of degrees-of-freedom was applied (West et al., 2015). Model diagnostics included visual assessment of the normality assumption of residuals and homogeneous variance among treatment groups. To determine if there was an effect of PUFA infusion, we compared the control group versus the average of the LnA and ALA group using the orthogonal contrast $\left(\begin{array}{lll}1 & -0.5 & -0.5\end{array}\right)$. Further, to determine the effect of PUFA type, we compared the LnA group with the ALA group using the following orthogonal contrast and $\left(\begin{array}{lll}0 & 1 & -1\end{array}\right)$. Differences in fatty acid and oxylipid concentrations due to $S$. uberis or LPS exposure compared with unstimulated CON samples were determined by Student's $t$-tests. Significance was set at $P \leq 0.05$ for all tests.

\section{RESULTS}

\section{Blood Leukocyte and Plasma Fatty Acid Concentrations Following Supplementation of $\operatorname{LnA}$ and $A L A$}

To determine the efficacy of LnA and ALA supplementation (in the absence of ex vivo microbial agonist challenge), leukocyte and plasma fatty acid concentrations were analyzed. Though LnA and ALA supplementation numerically altered fatty acid content in the leukocyte, fatty acid supplementation did not significantly change leukocyte fatty acid content relative to nonsupplemented cows (Figure 1, left panel of graph, and Table 3). Plasma changes were in contrast to leukocyte where ALA, palmitic acid, oleic acid, stearic acid, n-3 PUFA, the ratio of plasma n-6 PUFA/n-3 PUFA, and the ratio of plasma LnA/ALA were all significantly changed by fatty acid supplementation (Table 3). Some of these plasma changes were source dependent for ALA with greater ALA $(P=0.005)$, increased sum of n-3 PUFA $(P=0.003)$, and reduced ratios of n- 6 PUFA $/$ n-3 PUFA $(P<0.0001)$ and LnA/ALA $(P=$ 0.0002 ) relative to LnA supplementation (Figure 1, 2 right panel of graph, and Table 3). 

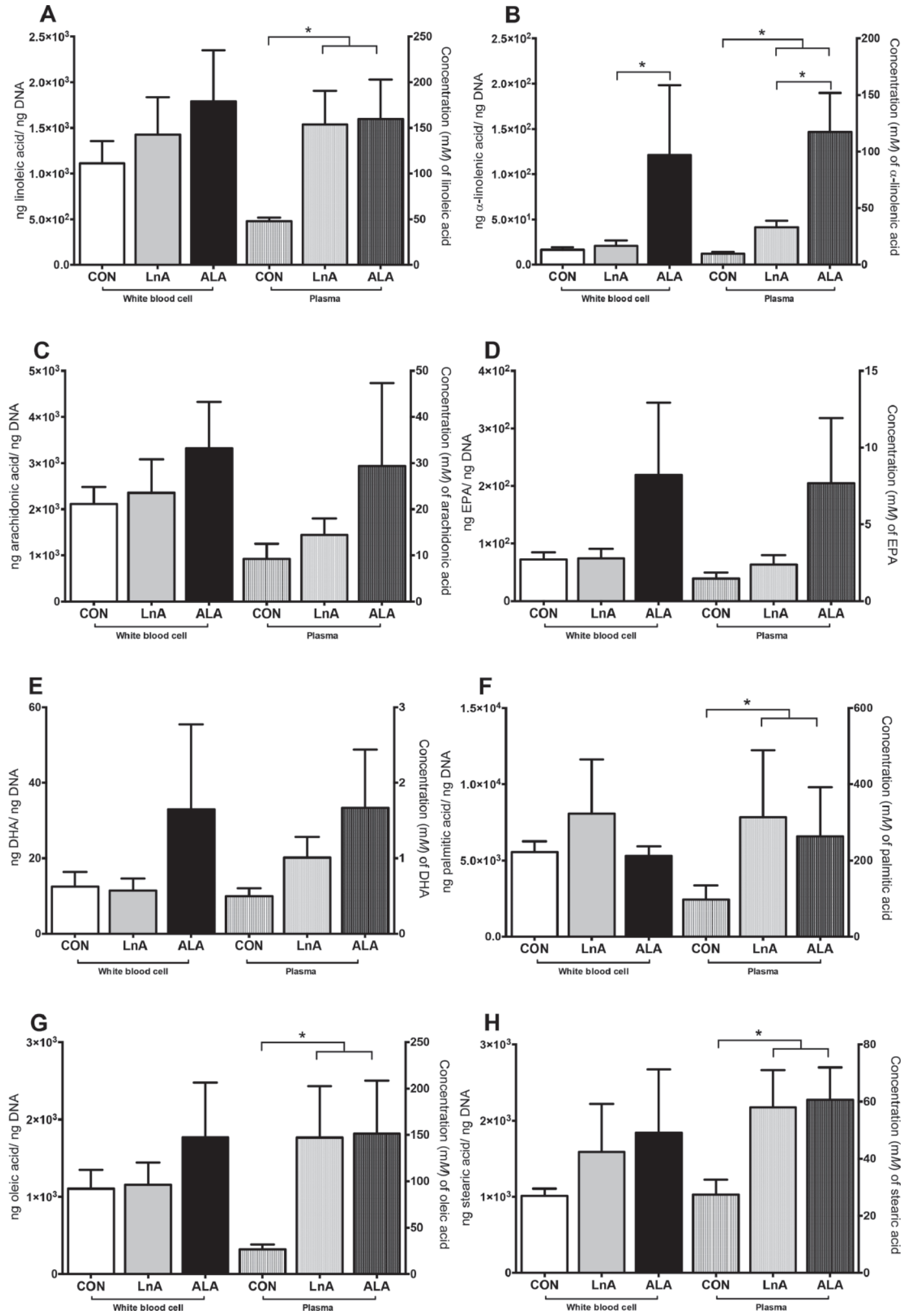

Figure 1. Normalized amount (ng of fatty acids/ng of DNA) of PUFA, SFA, and MUFA in bovine white blood cells is displayed in the left panel of each graph and plasma concentration $(\mathrm{m} M)$ of PUFA. SFA, and MUFA is displayed in the right panel of each graph following supplementation of the ethanol carrier (CON), linoleic acid (LnA) at $45 \mathrm{~g} / \mathrm{d}$, or $\alpha$-linolenic acid (ALA) at $45 \mathrm{~g} / \mathrm{d}$. Panels A-E depict quantified PUFA [LnA, ALA, arachidonic acid, eicosapentaenoic acid (EPA), and docosahexaenoic acid (DHA)]. Panels F-H depict quantified MUFA and SFA (oleic acid, palmitic acid, and stearic acid). Asterisks denote $P \leq 0.05$ for CON versus the average of LnA and ALA treatments or LnA versus ALA. Error bars indicate \pm SEM. 
Table 3. P-values for comparisons of fatty acid (FA) concentrations, sum of FA, and ratio of FA between treatment groups (CON, LnA, ALA) following abomasal FA supplementation in white blood cells and plasma ${ }^{1}$

\begin{tabular}{|c|c|c|c|c|}
\hline \multirow{3}{*}{$\begin{array}{l}\text { Fatty acid, } \Sigma \text { PUFA, } \\
\text { or ratio of PUFA }\end{array}$} & \multicolumn{4}{|c|}{$P$-value ${ }^{2}$} \\
\hline & \multicolumn{2}{|c|}{ White blood cells } & \multicolumn{2}{|c|}{ Plasma } \\
\hline & $\mathrm{CON}$ vs. $\mathrm{Avg}^{3}$ & LnA vs. ALA & $\mathrm{CON}$ vs. $\mathrm{Avg}^{3}$ & LnA vs. ALA \\
\hline LnA & 0.44 & 0.75 & 0.007 & 0.61 \\
\hline ArA & 0.56 & 0.32 & 0.10 & 0.43 \\
\hline ALA & 0.11 & 0.03 & 0.01 & 0.005 \\
\hline $\mathrm{EPA}$ & 0.49 & 0.16 & 0.08 & 0.11 \\
\hline DHA & 0.62 & 0.30 & 0.34 & 0.93 \\
\hline Palmitic acid & 0.87 & 0.52 & 0.02 & 0.99 \\
\hline Oleic acid & 0.59 & 0.55 & 0.002 & 0.89 \\
\hline Stearic acid ${ }^{4}$ & 0.54 & 0.89 & 0.01 & 0.51 \\
\hline इn-6 PUFA & 0.46 & 0.40 & 0.009 & 0.43 \\
\hline इn-3 PUFA ${ }^{4}$ & 0.33 & 0.12 & 0.0001 & 0.003 \\
\hline Ratio of n-6 PUFA/n-3 PUFA & 0.24 & 0.01 & 0.0004 & $<0.0001$ \\
\hline Ratio of LnA/ALA & 0.06 & 0.001 & 0.0009 & 0.0002 \\
\hline
\end{tabular}

${ }^{1} \mathrm{LnA}=$ linoleic acid, $\mathrm{ArA}=$ arachidonic acid, $\mathrm{ALA}=\alpha$-linolenic acid, EPA $=$ eicosapentaenoic acid, $\mathrm{DHA}=$ docosahexaenoic acid, CON = ethanol carrier, $\Sigma$ n-6 PUFA = sum of n-6 PUFA (ArA and LnA), Ln-3 PUFA $=$ sum of n-3 PUFA (ALA, EPA, and DHA).

${ }^{2} P$-values represent level of significance when analyzing orthogonal contrasts CON vs. Avg and LnA vs. ALA.

${ }^{3} \mathrm{CON}$ vs. the average of LnA and ALA treatments.

${ }^{4}$ Nonnormal residuals.

\section{Fatty Acids and Oxylipids Following Microbial Agonist Challenge Without PUFA Supplementation}

Whole blood exposed to heat-killed S. uberis for 4 $\mathrm{h}$ resulted in numerical decreases in all plasma PUFA, but only plasma ArA was significantly decreased (Table 4). In contrast, whole blood exposed to LPS for $4 \mathrm{~h}$ did not reveal any differences in plasma fatty acids (Table 4). Heat-killed S. uberis exposure of whole blood induced an increase in LnA-derived, ArA-derived, and EPA-derived oxylipids from the LOX and CYP oxidation pathways (Table 5). Heat-killed S. uberis increased biosynthesis of 13-oxooctadecadienoic acid (oxoODE, $P=0.03), 15$-oxoETE $(P=0.01), 12$-HETE $(P=0.01)$, 14,15-DiHETE $(P=0.05)$, and 17,18 -DiHETE $(P=$ 0.05 , Table 5). Oxylipids not significantly changed in response to S. uberis are displayed in Appendix Table A1.

All oxylipids changed by LPS exposure were derived from ArA and represented all 3 enzymatic pathways: cyclooxygenase, LOX, and CYP (Table 5). Lipopolysaccharide challenge increased 12- hydroxyheptadecatrienoic acid $(P=0.03)$, but decreased $5,6-\mathrm{LXA}_{4}(P$ $=0.05)$ and 11,12-epoxyeicosatrienoic acid $(P=$ $0.03)$. The ratio of 11,12 -EET/11,12-DHET was also decreased $(P=0.05)$, suggesting a greater abundance of the downstream DHET compared with EET during LPS exposure relative to unstimulated plasma oxylipid profiles from bovine leukocytes. However, because the ratio of 11,12-EET/11,12-DHET is below 1, DHET is abundant regardless of inflammatory challenge. Oxy- lipids not significantly changed in response to LPS are displayed in Appendix Table A1.

\section{Microbial Agonist Challenge-Induced Fatty Acids and Oxylipid Changes Following LnA and ALA Supplementation}

Plasma fatty acids were not altered following $S$. uberis stimulation (Table 6). In contrast, fatty acid supplementation significantly affected the $S$. uberis-induced synthesis of 9-HETE, 8-iso-PGF ${ }_{2 \alpha}$, and 15-oxoETE, but only the $S$. uberis-induced 15-oxoETE $(P=0.02)$ was source dependent between LnA and ALA supplemented groups (Table 7). Streptococcus uberis-induced oxylipids that were not changed by treatments are in Appendix Table A2.

The LPS-induced plasma fatty acids were not altered with fatty acid supplementation (Table 8). Fatty acid supplementation, regardless of source, affected the LPS-induced synthesis of $5,6-\mathrm{LXA}_{4}(P=0.03)$, though no difference $(P=0.20)$ was found between LnA and ALA groups (Table 9). The LPS-induced oxylipids that were not changed by treatments are in Appendix Table A3.

\section{DISCUSSION}

The availability or relative abundance of cellular PUFA content contributes to distinct oxylipid profiles during homeostasis and disease. Indeed, altering PUFA content in host cells is being pursued as a strategy to 
Table 4. Concentration $(\mathrm{m} M)$ of plasma fatty acids (FA) following ex vivo microbial exposure ${ }^{1}$

\begin{tabular}{|c|c|c|c|c|c|c|c|c|}
\hline Fatty acid $^{2}$ & \multicolumn{2}{|c|}{ Unstimulated } & \multicolumn{3}{|c|}{ Streptococcus uberis } & \multicolumn{3}{|c|}{ LPS } \\
\hline $\operatorname{Ln} A$ & 225.56 & 44.13 & 188.15 & 41.84 & 0.52 & 273.01 & 82.56 & 0.52 \\
\hline ALA & 54.09 & 10.34 & 45.76 & 9.46 & 0.51 & 57.04 & 16.00 & 0.82 \\
\hline EPA & 5.69 & 1.81 & 2.52 & 0.52 & 0.08 & 5.72 & 2.33 & 0.99 \\
\hline DHA & 1.61 & 0.33 & 1.26 & 0.26 & 0.36 & 1.84 & 0.47 & 0.68 \\
\hline
\end{tabular}

${ }^{1}$ Blood samples from the nonsupplemented group (CON) were collected and exposed to heat-killed S. uberis or LPS for 4 h. Plasma then was collected and plasma FA were quantified by liquid chromatography-MS.

${ }^{2} \mathrm{LnA}=$ linoleic acid, ArA = arachidonic acid, ALA = $\alpha$-linolenic acid, EPA = eicosapentaenoic acid, DHA = docosahexaenoic acid

${ }^{3}$ Arithmetic means are shown for unstimulated, heat-killed $S$. uberis-challenged, and LPS-challenged plasma FA concentrations.

${ }^{4} P$-values correspond to microbial exposure $(S$. uberis or LPS) relative to unstimulated as determined by paired Student's $t$-tests $(P \leq 0.05)$.
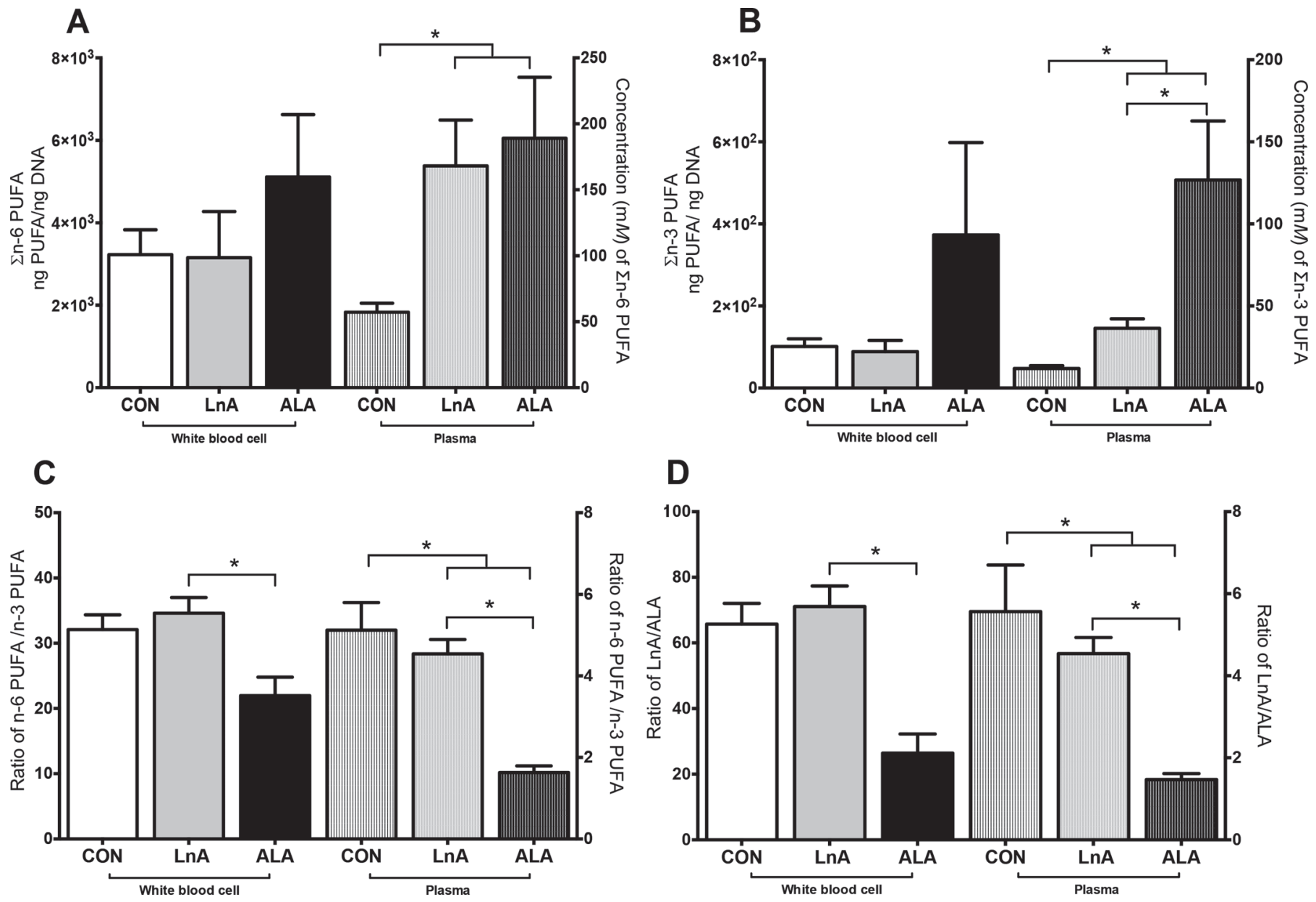

Figure 2. Normalized average sum of n- 6 fatty acids (FA; ng of FA/ng of DNA), n-3 FA (ng of FA/ng of DNA), ratio of n-6/n-3, and ratio of linoleic acid ( $\mathrm{LnA}) / \alpha$-linolenic acid (ALA) in bovine white blood cells is displayed in the left panel of each graph and average sum concentration of n-6 PUFA, n-3 PUFA, ratio of n-6/n-3, and ratio of LnA/ALA in plasma is displayed in the right panel of each graph following supplementation of the ethanol carrier $(\mathrm{CON})$, LnA at $45 \mathrm{~g} / \mathrm{d}$, or ALA at $45 \mathrm{~g} / \mathrm{d}$. Panel A represents the normalized sum of n-6 PUFA (LnA and arachidonic acid). Panel B represents the normalized sum of n-3 PUFA [ALA, eicosapentaenoic acid (EPA), and docosahexaenoic acid (DHA)]. Panel C represents the ratio of total n-6 to n-3 (n-6/n-3). Panel D represents the ratio of LnA to ALA (LnA/ALA). Asterisks denote $P \leq 0.05$ for CON versus the average of LnA and ALA treatments or LnA versus ALA. Error bars indicate \pm SEM. 
Table 5. Concentration $(\mu M)$ of significantly changed plasma oxylipids following ex vivo microbial agonist exposure ${ }^{1,2}$

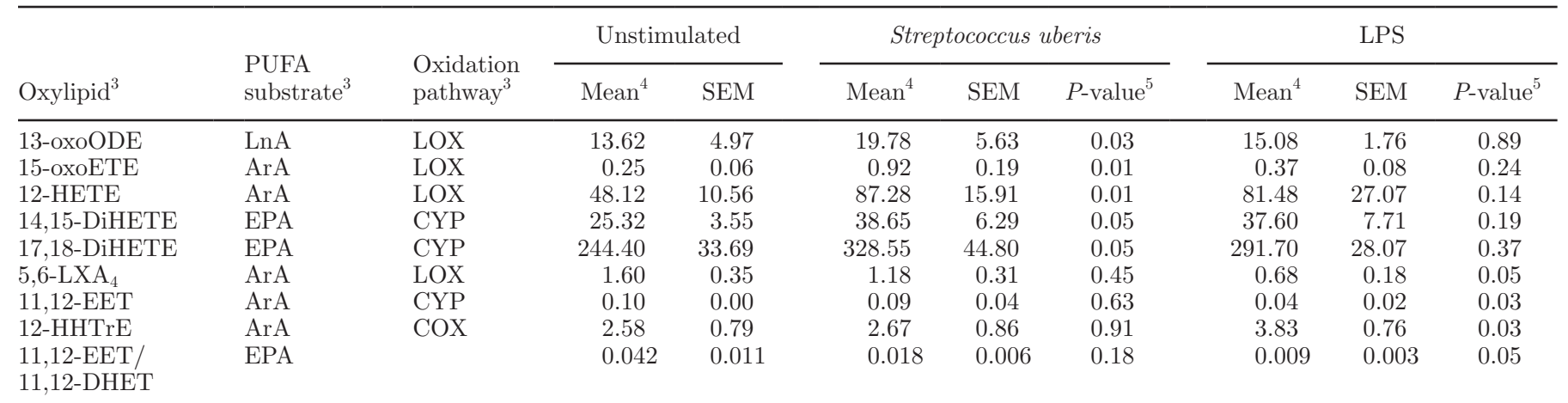

${ }^{1}$ Blood samples from the nonsupplemented group (CON) were collected and exposed to heat-killed S. uberis or LPS for 4 h. Plasma then was collected and oxylipids were quantified by liquid chromatography-MS/MS.

${ }^{2}$ Only oxylipids significantly changed following S. uberis or LPS exposure relative to control are displayed.

${ }^{3}$ oxoODE $=$ oxooctadecadienoic acid, oxoETE $=$ oxoeicosatetraenoic acid, HETE $=$ hydroxyeicosatetraenoic acids, LX $=$ lipoxin, EET $=$ epoxyeicosatrienoic acid, DHET = dihydroxyeicosatrienoic acid, HHTrE = hydroxyheptadecatrienoic acid, DiHETE = dihydroxyeicosatetraenoic acid, $\mathrm{LnA}=$ linoleic acid, ArA $=$ arachidonic acid, EPA = eicosapentaenoic acid, LOX = lipoxygenase, CYP $=$ cytochrome $\mathrm{P} 450, \mathrm{COX}=$ cyclooxygenase.

${ }^{4}$ Arithmetic means are shown for unstimulated, heat-killed $S$. uberis-challenged, and LPS-challenged plasma oxylipid concentrations.

${ }^{5} P$-values correspond to microbial exposure ( $S$. uberis or LPS) relative to unstimulated as determined by paired Student's $t$-tests $(P \leq 0.05)$.

modify oxylipid biosynthesis in hopes of mitigating inflammation and reducing disease severity (Duda et al., 2009; Raphael and Sordillo, 2013; Min et al., 2014). Increasing n-3 fatty acids, such as ALA, is a common approach to mitigate disease primarily given its availability for conversion to EPA and DHA, which may be oxidized to a variety of anti-inflammatory oxylipids. Supplementation of ALA relative to LnA treatment significantly increased ALA content of leukocyte in the present trial. However, supplementation of ALA relative to LnA treatment did not result in increased EPA and DHA content of leukocyte, perhaps as a consequence of insufficient dose or length of time with supplementation. A recent review concluded, based on a summary of ALA-supplementation trials, up to $40 \mathrm{~g} / \mathrm{d}$ (a high dose for humans) and as many as 42 wk was required to consistently modify EPA content, with little to no appreciable change in DHA content (Brenna et al., 2009). Additionally, elongase and desaturase enzyme activities were not evaluated in the study but may affect ALA conversion because the same elongase and desaturase enzymes may metabolize both LnA and ALA (Guillou et al., 2010). Thus, the abundance of LnA in the diet and in the leukocyte may outcompete ALA for

Table 6. Changes in plasma fatty acids (FA) from PUFA-supplemented cows following ex vivo Streptococcus uberis challenge ${ }^{1}$

\begin{tabular}{|c|c|c|c|c|c|c|c|c|}
\hline \multirow[b]{3}{*}{ Fatty acid } & \multicolumn{6}{|c|}{ Treatment } & \multicolumn{2}{|c|}{$P$-value ${ }^{2}$} \\
\hline & \multicolumn{2}{|c|}{$\mathrm{CON}$} & \multicolumn{2}{|c|}{$\operatorname{LnA}$} & \multicolumn{2}{|c|}{ ALA } & \multirow[b]{2}{*}{$\begin{array}{c}\mathrm{CON} \\
\text { vs. } \mathrm{Avg}^{3}\end{array}$} & \multirow[b]{2}{*}{$\begin{array}{c}\operatorname{Ln} A \\
\text { vs. ALA }\end{array}$} \\
\hline & $\Delta$ Mean $^{4}$ & SEM & $\Delta$ Mean & SEM & $\Delta$ Mean & SEM & & \\
\hline $\operatorname{Ln} A$ & -37.41 & 54.73 & -93.37 & 68.90 & +86.07 & 113.24 & 0.78 & 0.28 \\
\hline $\mathrm{ArA}$ & -15.42 & 6.27 & -8.19 & 5.18 & +9.30 & 6.62 & 0.16 & 0.09 \\
\hline ALA & -8.34 & 11.82 & -51.76 & 13.86 & -3.95 & 93.56 & 0.86 & 0.70 \\
\hline Palmitic acid & -189.16 & 175.84 & +59.86 & 543.60 & +399.64 & 238.69 & 0.43 & 0.52 \\
\hline Oleic acid & -9.55 & 24.11 & -34.59 & 27.34 & +72.61 & 76.61 & 0.68 & 0.28 \\
\hline Stearic acid & +20.04 & 26.05 & +1.22 & 9.63 & +58.04 & 24.75 & 0.82 & 0.03 \\
\hline
\end{tabular}

${ }^{1} \mathrm{LnA}=$ linoleic acid, $\mathrm{ArA}=$ arachidonic acid, $\mathrm{ALA}=\alpha$-linolenic acid, $\mathrm{EPA}=$ eicosapentaenoic acid, DHA $=$ docosahexaenoic acid, $\mathrm{CON}=$ ethanol carrier.

${ }^{2} P$-values represent level of significance when analyzing orthogonal contrasts CON vs. Avg and LnA vs. ALA.

${ }^{3} \mathrm{CON}$ vs. the average of LnA and ALA treatments.

${ }^{4} \Delta$ Mean for each replicate was quantified by subtracting $S$. uberis-induced plasma FA concentration $(\mathrm{m} M)$ from unstimulated plasma FA concentration $(\mathrm{m} M)$. Means in table represent arithmetic means. A + indicates greater plasma FA following $S$. uberis exposure compared with unstimulated samples, whereas - indicates less plasma FA following S. uberis exposure compared with unstimulated samples. 
Table 7. Changes in plasma oxylipids from PUFA-supplemented cows following ex vivo Streptococcus uberis challenge ${ }^{1}$

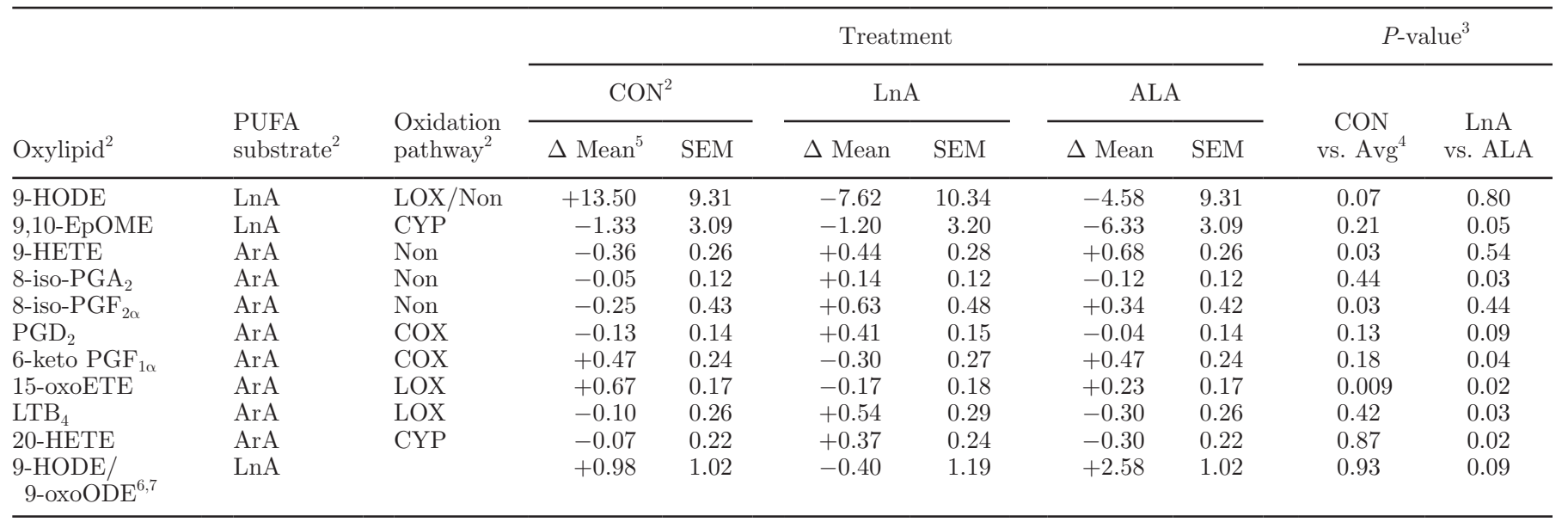

${ }^{1}$ Only oxylipids demonstrating a significant or trending difference are displayed.

${ }^{2} \mathrm{HODE}=$ hydroxyoctadecadienoic acid, EpOME = epoxyoctadecenoic acid, oxoODE $=$ oxooctadecadienoic acid, HETE $=$ hydroxyeicosatetraenoic acid, $\mathrm{PG}=$ prostaglandin, $\mathrm{LT}=$ leukotriene, oxoETE $=$ oxoeicosatetraenoic acid, $\mathrm{LnA}=$ linoleic acid, ArA $=$ arachidonic acid, $\mathrm{CYP}$ $=$ cytochrome P450, LOX = lipoxygenase, Non = nonenzymatic, $\mathrm{COX}=$ cyclooxygenase, $\mathrm{CON}=$ ethanol carrier, $\mathrm{ALA}=\alpha$-linolenic acid.

${ }^{3} P$-values represent level of significance when analyzing orthogonal contrasts CON versus Avg and LnA versus ALA.

${ }^{4} \mathrm{CON}$ vs. the average of LnA and ALA treatments.

${ }^{5} \Delta$ Mean for each replicate was quantified by subtracting $S$. uberis-induced plasma oxylipid concentrations $(\mu M)$ from unstimulated plasma oxylipid concentrations $(\mu M)$. Means in table represent arithmetic means. A + indicates greater plasma oxylipids following $S$. uberis exposure compared with unstimulated samples, whereas - indicates less plasma oxylipids following $S$. uberis exposure compared with unstimulated samples. ${ }^{6}$ Nonnormal residuals.

${ }^{7}$ Heterogenous variance.

elongation and desaturation. Although our data do not fully support this claim because no change occurred in LnA or ArA content, we also did not measure all intermediary PUFA that may compete for elongases and desaturases (Patterson et al., 2012). In addition to the possibility of differential elongase and desatu- rase activity affecting PUFA content, the ability for fatty acid incorporation into the cell can influence fatty acid content changes with supplementation. Previous research also suggested there was no discrimination between incorporation of n-6 or n-3 PUFA and that the availability of PUFA in the phospholipid membrane is

Table 8. Changes in plasma fatty acids (FA) from PUFA-supplemented cows following ex vivo LPS challenge ${ }^{1}$

\begin{tabular}{|c|c|c|c|c|c|c|c|c|}
\hline \multirow[b]{3}{*}{ Fatty acid } & \multicolumn{6}{|c|}{ Treatment } & \multicolumn{2}{|c|}{$P$-value ${ }^{2}$} \\
\hline & \multicolumn{2}{|c|}{$\mathrm{CON}$} & \multicolumn{2}{|c|}{$\operatorname{Ln} A$} & \multicolumn{2}{|c|}{ ALA } & \multirow[b]{2}{*}{ CON vs. $\mathrm{Avg}^{3}$} & \multirow[b]{2}{*}{ LnA vs. ALA } \\
\hline & $\Delta$ Mean $^{4}$ & SEM & $\Delta$ Mean & SEM & $\Delta$ Mean & SEM & & \\
\hline $\operatorname{LnA}$ & +47.45 & 68.94 & -29.59 & 45.98 & +120.79 & 27.12 & 0.94 & 0.06 \\
\hline $\mathrm{ArA}$ & +1.80 & 14.25 & +8.51 & 10.88 & +4.27 & 2.66 & 0.69 & 0.75 \\
\hline ALA & +2.94 & 12.31 & -21.05 & 9.25 & +60.83 & 26.00 & 0.54 & 0.01 \\
\hline Palmitic acid & +928.23 & 745.06 & +37.33 & 413.70 & +678.18 & 292.73 & 0.36 & 0.37 \\
\hline Oleic $\operatorname{acid}^{5}$ & +8.67 & 48.62 & -22.28 & 30.73 & +74.13 & 25.23 & 0.82 & 0.15 \\
\hline Stearic acid & +51.67 & 51.58 & +2.38 & 17.26 & +72.20 & 55.02 & 0.73 & 0.25 \\
\hline
\end{tabular}

${ }^{1} \mathrm{LnA}=$ linoleic acid, $\mathrm{ArA}=$ arachidonic acid, $\mathrm{ALA}=\alpha$-linolenic acid, $\mathrm{EPA}=$ eicosapentaenoic acid, $\mathrm{DHA}=$ docosahexaenoic acid, $\mathrm{CON}=$ ethanol carrier.

${ }^{2} P$-values represent level of significance when analyzing orthogonal contrasts CON vs. Avg and LnA vs. ALA.

${ }^{3} \mathrm{CON}$ vs. the average of LnA and ALA treatments.

${ }^{4} \Delta$ Mean for each replicate was quantified by subtracting LPS-induced plasma FA concentration ( $m M$ ) from unstimulated plasma fatty acid concentration $(\mathrm{m} M)$. Means in table represent arithmetic means. A + indicates greater plasma FA following LPS exposure compared with unstimulated samples, whereas - indicates less plasma fatty acids following LPS exposure compared with unstimulated samples.

${ }^{5}$ Nonnormal residuals. 
reflective of dietary intake (Lands et al., 1982; Dougherty et al., 1987). Though the potential for a maximal level of PUFA incorporation has yet to be thoroughly considered, an in vitro epithelial cell line study demonstrated that $50 \%$ of maximal incorporation of ALA was achieved by 10 to $20 \mu \mathrm{g} / \mathrm{mL}$, whereas $50 \%$ of maximal incorporation of LnA was at only 5 to $10 \mu \mathrm{g} / \mathrm{mL}$ (Bryan et al., 2001). Furthermore, previous research also indicated a potential negative effect of excess PUFA on the ability to incorporate PUFA by acyltransferases. In humans pre-fed a high LnA diet before receiving LnA or ALA, acyltransferase activity appeared reduced compared with humans pre-fed a high SFA diet (Emken et al., 1994). Authors hypothesized that the high LnA in the prefed diet might decrease acyltransferase mRNA synthesis, support increase transport to the mitochondria for $\beta$-oxidation, or divert excess PUFA to adipose tissue for storage. Although conjecture, current and previous data suggest supplementation of PUFA already in abundance may prohibit further incorporation or changes in leukocyte PUFA content and thus affect oxylipid biosynthesis.

A complex network of oxylipids is synthesized in response to a variety of stimuli, including bacteria and bacterial-derived agonists. Previous studies supported the differential biosynthesis of oxylipids to gram-negative and gram-positive agonists, perhaps as a result of pathogen-associated molecular patterns recognition during bovine mastitis (Tam, 2013; Mavangira et al., 2015; Ryman et al., 2015). Thus, it was not surprising that ex vivo exposure to LPS and S. uberis resulted in different oxylipid profiles because LPS mediates the inflammatory response through toll-like receptor-4, whereas the response to $S$. uberis is generally considered to be dependent on lipoteichoic acid binding to toll-like receptor-2 (Bannerman et al., 2004a). It is possible that other S. uberis-derived secreted toxins could contribute to differential oxylipid biosynthesis (Oliver et al., 1998). The most striking difference in oxylipid profiles within the current study was that LPS contributed to a reduction in oxylipids with anti-inflammatory properties, whereas the inverse was true for S. uberis. Exposure to LPS in the current study reduced anti-inflammatory $\mathrm{LXA}_{4}$ and 11,12-EET biosynthesis, which previous studies demonstrated are necessary for maintenance of the endothelial barrier and control of pro-inflammatory cytokine expression (Schmelzer et al., 2005; Ereso et al., 2009). In contrast, S. uberis exposure induced biosynthesis of oxylipids that are ligands for activation of a nuclear receptor called peroxisome proliferatoractivated receptor- $\gamma$ that can inhibit pro-inflammatory nuclear factor-kB signaling (Zhao et al., 2004; Shiraki et al., 2005; Snyder et al., 2015). The significance of these changes in the context of mastitis was not elucidated in the current study, but highlighted a need to understand if different pathogen recognition receptor signaling pathways can directly mediate oxylipid biosynthesis (Strandberg et al., 2005).

The inflammatory response to LPS during coliform mastitis contributes to the production of lipid mediators from many different cell types. Thus, it was not surprising that fewer changes in oxylipids were induced by ex vivo LPS exposure of leukocytes compared with milk and plasma profiles during coliform mastitis

Table 9. Changes in plasma oxylipids from PUFA-supplemented cows following ex vivo LPS challenge ${ }^{1}$

\begin{tabular}{|c|c|c|c|c|c|c|c|c|c|c|}
\hline \multirow[b]{2}{*}{ Oxylipid $^{2}$} & \multirow[b]{2}{*}{$\begin{array}{l}\text { PUFA } \\
\text { substrate }^{2}\end{array}$} & \multirow[b]{2}{*}{$\begin{array}{l}\text { Oxidation } \\
\text { pathway }^{2}\end{array}$} & \multicolumn{6}{|c|}{ Treatment } & \multicolumn{2}{|c|}{$P$-value ${ }^{3}$} \\
\hline & & & $\Delta$ Mean $^{5}$ & SEM & $\Delta$ Mean & SEM & $\Delta$ Mean & SEM & $\begin{array}{c}\mathrm{CON} \\
\text { vs. } \mathrm{Avg}^{4}\end{array}$ & $\begin{array}{c}\text { LnA } \\
\text { vs. ALA }\end{array}$ \\
\hline $5,6 \mathrm{LXA}_{4}$ & ArA & LOX & +0.92 & 0.35 & -0.23 & 0.39 & +0.37 & 0.35 & 0.03 & 0.20 \\
\hline $\mathrm{PGE}_{2}$ & ArA & COX & -0.95 & 0.55 & +0.46 & 0.63 & +0.33 & 0.55 & 0.09 & 0.89 \\
\hline 9-oxoODE & LnA & LOX/Non & -12.48 & 8.30 & -30.25 & 9.59 & +30.42 & 8.3 & 0.32 & 0.06 \\
\hline $\begin{array}{l}\text { 13-HODE/ } \\
13 \text {-oxoODE }\end{array}$ & $\operatorname{Ln} A$ & & -6.39 & 5.31 & -6.31 & 5.90 & -22.16 & 5.31 & 0.29 & 0.08 \\
\hline
\end{tabular}

${ }^{1}$ Only oxylipids demonstrating a significant or trending difference are displayed.

${ }^{2} \mathrm{LX}=$ lipoxin, $\mathrm{PG}=$ prostaglandin, HODE $=$ hydroxyoctadecadienoic acid, oxoODE $=$ oxooctadecadienoic acid, $\mathrm{LnA}=$ linoleic acid, ArA $=$ arachidonic acid, LOX = lipoxygenase, Non = nonenzymatic, $\mathrm{COX}=$ cyclooxygenase, $\mathrm{CON}=$ ethanol carrier.

${ }^{3} P$-values represent level of significance when analyzing orthogonal contrasts CON vs. Avg and LnA vs. ALA.

${ }^{4} \mathrm{CON}$ vs. the average of LnA and ALA treatments.

${ }^{5} \Delta$ Mean for each replicate was quantified by subtracting LPS-induced plasma oxylipid concentrations $(\mu M)$ from unstimulated plasma oxylipid concentrations $(\mu M)$. Means in table represent arithmetic means. A + indicates greater plasma oxylipids following LPS exposure compared with unstimulated samples, whereas - indicates less plasma oxylipids following LPS exposure compared with unstimulated samples.

${ }^{6}$ Nonnormal residuals.

${ }^{7}$ Heterogenous variance. 
(Mavangira et al., 2015). However, the contribution of replicating E. coli bacteria, sustained exposure to LPS release, and the participation of a variety of cells and tissues probably led to a more diverse oxylipid profile. Furthermore, the ex vivo model could not capture the contribution of adipose tissue lipolysis, which may be important for oxylipid biosynthesis as it is proposed to be the primary source of nonesterified fatty acids during LPS-mediated inflammation (Zu et al., 2009; Moyes et al., 2014). This limitation may be supported by the absence of any changes in nonesterified $\mathrm{LnA}$ in the current study compared with an almost 3 -fold increase measured in milk and plasma during bovine coliform mastitis (Mavangira et al., 2015). Additionally, a different LPS dose or duration of challenge could contribute to a more diverse ex vivo oxylipid profile, recapitulating in vivo data more closely. Though the current model had limitations, ex vivo exposure of leukocyte may be critical in understanding the specific contributions to oxylipid biosynthesis of blood leukocytes during LPS exposure. In fact, some similarities in oxylipid biosynthesis were detected between ex vivo and in vivo studies. Decreased anti-inflammatory 5,6-LXA ${ }_{4}$ and 11,12-EET in the current study were consistent with plasma oxylipids during coliform mastitis, but inverse to the change in milk oxylipids (Mavangira et al., 2015). The authors hypothesized that the inverse relationship between milk and plasma oxylipids may be the result, in part, of a breakdown in the blood-milk barrier. Our findings may suggest the oxylipid production from blood cells also decreased, which could contribute to reduced plasma oxylipid expression during coliform mastitis.

Oxylipid profiles induced by $S$. uberis in the current study also were in contrast to previous work. For example, intramammary $S$. uberis challenge did not induce changes in milk oxylipids, whereas the current study demonstrated increases in ArA-, LnA-, and EPA-derived oxylipids (Ryman et al., 2015). The lack of changes in milk oxylipids following intramammary S. uberis challenge compared with current findings may be attributed, in part, to the difference in the size of the quantified oxylipid panel. For example, the current study included a much wider oxylipid profile, especially including more CYP- and EPA-derived oxylipids than the previous work (Ryman et al., 2015). A wider profile in the current study may be the reason we were able to report increased 14,15-DiHETE and 17,18-DiHETE, though their functions in the inflammatory response are unknown. Similarly, 12-HETE was not previously quantified in milk or tissue from $S$. uberis challenge, yet our ex vivo results demonstrated an $S$. uberis-induced increase. However, the inflammatory properties of 12 HETE are contradictory depending on the disease and cell model and warrant further investigation (Bolick et al., 2005; Kronke et al., 2009). Whereas 13-oxoODE and 15-oxoETE, both ligands for PPAR- $\gamma$, were quantified in milk and tissue from $S$. uberis challenge animals similar to the current study, only ex vivo exposure of leukocytes to $S$. uberis resulted in increased biosynthesis. The inconsistency of 13-oxoODE and 15-oxoETE biosynthesis between the current study and intramammary $S$. uberis challenge may be a function of different stages of inflammation, in the case of $S$. uberis tissue, or dilution of oxylipids in milk limiting the detection of appreciable changes. A final important finding was that, in general, significantly changed $S$. uberis-induced oxylipids (oxoODE, oxoETE, and DiHETE) represented a greater degree of metabolism from their precursors. It is unknown how $S$. uberis recognition and the subsequent immune response may influence the activity of downstream enzymatic metabolism in leukocytes, but may be important when developing pharmacologic intervention strategies during mastitis.

Aside from the likely contribution of pathogen recognition pathways, oxylipid profiles depend on abundance and proportion of cellular PUFA content. In the current study, the primary goal of supplementation was to modify cellular PUFA content, and thus, alter microbial agonist-induced oxylipid profiles. As discussed earlier, we demonstrated in the present study that fatty acid supplementation for $7 \mathrm{~d}$ did not modify PUFA leukocyte content. However, fatty acid supplementation could have affected other levels of the oxylipid biosynthetic pathway besides substrate availability during microbial exposure, including method of oxidation and degree of metabolism (Ramsden et al., 2012; Mavangira et al., 2015). Our data support a potential effect of fatty acid supplementation on oxidation pathway during S. uberis exposure because oxylipids that were significantly affected by fatty acid supplementation represented both enzymatic (15-oxoETE from 15-LOX) and nonenzymatic oxidation pathways (9-HETE and 8-iso-PGF ${ }_{2 \alpha}$ ). The effect of fatty acid supplementation on degree of metabolism was not conclusive because even though 15-oxoETE was decreased with fatty acid treatment, no change occurred in the ratio of upstream hydroxyl 15-HETE to its downstream ketone 15-oxoETE. The reason for a decrease 15-oxoETE is unclear, but previous data demonstrated an inhibitory effect of PUFA on some CYP isoforms and the ability of 15-LOX-1 to undergo suicide inactivation due to its own metabolites (Wiesner et al., 2003; Yao et al., 2006). Additional studies are required to understand how supplemental PUFA, without a change in leukocyte PUFA content, may affect method of fatty acid oxidation during a microbial agonist challenge.

Interestingly, our findings from evaluating $S$. uberisinduced oxylipids suggested an increase in lipid per- 
oxidation with fatty acid supplementation because $S$. uberis-induced nonenzymatically derived 9-HETE and 8 -iso-PGF $\mathrm{PG}_{2 \alpha}$ was greater with fatty acid supplementation relative to no PUFA supplementation. Lipid peroxidation is implicated in dysfunctional inflammatory responses and inflammatory-based diseases (Catala, 2009). Though no difference was found between LnA and ALA supplemented groups for 9-HETE, the $S$. uberis-induced biosynthesis was numerically higher with ALA supplementation relative to LnA supplementation, which is counterintuitive to the perceived positive attributes of ALA. Feeding whole linseed as a source of ALA is a common approach in dairy cows to increase anti-inflammatory n-3 fats, such as EPA and DHA, in milk because milk composition is negatively affected by fish oil supplementation (Petit et al., 2002). However, our findings suggest that supplementation with either PUFA could contribute to increased peroxidation of lipid membranes during S. uberis infection. Increased fatty acid availability, with no appreciable decreases in other PUFA, would increase the availability of PUFA for lipid peroxidation (Guido et al., 1993). Demonstrating a PUFA-induced increase in markers of lipid peroxidation indicates that further studies are required to understand how both excess LnA and ALA may affect pathogen-induced immune responses. Although outside the scope of the current study, our data suggest that supplementing any PUFA could have an unintended negative consequence on disease outcome.

In contrast to $S$. uberis exposure, markers of lipid peroxidation were not increased by fatty acid supplementation during LPS challenge; however, the biosynthesis of LPS-induced ArA-derived 5,6-LXA 4 was significantly affected by fatty acid supplementation. Biosynthesis of $\mathrm{LXA}_{4}$ is instrumental in decreasing leukocyte recruitment and migration, as well as promoting resolution of inflammation (Serhan, 1994). Though no significant difference was found between LnA- and ALA-supplemented groups in LPS-induced $5,6-\mathrm{LXA}_{4}$ biosynthesis, a substantial numerical decrease occurred with LnA supplementation. Similarly, LPS-induced 9-oxoODE was trending lower with LnA supplementation compared with an increased in LPSinduced biosynthesis during ALA supplementation ( $P$ $=0.06$, Table 9). Perhaps manipulating the ratio of LnA/ALA with fatty acid supplementation contributed to the increased presentation of an anti-inflammatory oxylipid during LPS exposure (Poulsen et al., 2008). Similarly, 9-oxoODE are ligands for anti-inflammatory PPAR- $\gamma$ and adding exogenous 9-oxoODE to a macrophage model of oxidative stress deficient in 9-oxoODE decreased TNF- $\alpha$ release (Nagy et al., 1998; Itoh et al., 2008; Mattmiller et al., 2014). Perhaps decreasing the ratio of LnA/ALA with ALA supplementation relative to LnA, as the present study demonstrated, contributed to the presentation of a more anti-inflammatory profile during LPS exposure regardless of the oxylipid substrate (Poulsen et al., 2008). Given the contrasting findings with LPS- and S. uberis-induced oxylipid profiles with fatty acid supplementation, positive or negative effects of fatty acid supplementation may be different in the context of mastitis caused by either gram-negative or gram-positive pathogens. Additionally, given the use of linseed for ALA rather than fish oil for EPA and DHA in dairy cattle, future studies are needed to determine its efficacy in improving disease outcome in variety of inflammatory conditions, such as mastitis and metritis. Perhaps increased EPA- and DHA-derived oxylipids are not required if increasing the abundance of anti-inflammatory n-6 derived oxylipids, such as lipoxins and oxoODEs, can be consistently achieved.

\section{CONCLUSIONS}

Oxylipid biosynthesis during microbial exposure is dependent on several factors, including type of agonist and PUFA availability. Supplementation of ALA increased ALA content of leukocyte and decreased the ratio of LnA/ALA compared with LnA supplementation, but no change in EPA and DHA content suggested that dose or duration of ALA supplementation may be important for enhanced EPA and DHA content. Consistent with no change in EPA and DHA content after ALA supplementation, microbial-induced EPAand DHA-derived oxylipids were not increased with ALA treatment relative to LnA. However, LPS-induced anti-inflammatory oxylipids from n-6 fatty acids were numerically increased following ALA supplementation. Perhaps the ratio of $\mathrm{LnA}$ /ALA content is equally, if not more, important in mediating oxylipid biosynthesis during microbial agonist challenge than absolute abundance. Furthermore, data indicated that fatty acid supplementation could affect $S$. uberis-induced oxylipid biosynthesis without changing PUFA content in bovine leukocytes, suggesting that supplemental PUFA can affect other levels of oxylipid biosynthesis, like method of oxidation or degree of oxylipid metabolism. Though oxylipid profiles are inherently dependent on phospholipid PUFA content, the interaction with pathogen recognition pathways could contribute to modification of other regulatory levels of oxylipid biosynthesis, such as method of oxidation. The data presented in this manuscript are essential to enhancing our understanding of PUFA and oxylipid biosynthesis during different microbial exposures in the dairy cow. 


\section{ACKNOWLEDGMENTS}

This work funded from the Matilda R. Wilson Fund (Detroit, MI), the Agriculture and Food Research Initiative Competitive Grants Program of the USDA National Institute for Food and Agriculture (Washington, DC; 2011-67015-30179 and 2015-67011-23012), Rackham Research Endowment, and Michigan State University AgBioResearch. Technical assistance provided by Jeff Gandy and Courtney Preseault was instrumental in the completion of these experiments.

\section{REFERENCES}

Bannerman, D. D., M. J. Paape, J. P. Goff, K. Kimura, J. D. Lippolis, and J. C. Hope. 2004a. Innate immune response to intramammary infection with Serratia marcescens and Streptococcus uberis. Vet. Res. 35:681-700.

Bannerman, D. D., M. J. Paape, J. W. Lee, X. Zhao, J. C. Hope, and P. Rainard. 2004b. Escherichia coli and Staphylococcus aureus elicit differential innate immune responses following intramammary infection. Clin. Diagn. Lab. Immunol. 11:463-472.

Bolick, D. T., A. W. Orr, A. Whetzel, S. Srinivasan, M. E. Hatley, M. A. Schwartz, and C. C. Hedrick. 2005. 12/15-lipoxygenase regulates intercellular adhesion molecule-1 expression and monocyte adhesion to endothelium through activation of RhoA and nuclear factor-kappaB. Arterioscler. Thromb. Vasc. Biol. 25:2301-2307.

Brenna, J. T., N. Salem Jr., A. J. Sinclair, and S. C. Cunnane. 2009. alpha-Linolenic acid supplementation and conversion to n-3 longchain polyunsaturated fatty acids in humans. Prostaglandins Leukot. Essent. Fatty Acids 80:85-91.

Bryan, D. L., P. Hart, K. Forsyth, and R. Gibson. 2001. Incorporation of alpha-linolenic acid and linoleic acid into human respiratory epithelial cell lines. Lipids 36:713-717.

Buczynski, M. W., D. S. Dumlao, and E. A. Dennis. 2009. Thematic Review Series: Proteomics. An integrated omics analysis of eicosanoid biology. J. Lipid Res. 50:1015-1038.

Calder, P. C. 2008. The relationship between the fatty acid composition of immune cells and their function. Prostaglandins Leukot. Essent. Fatty Acids 79:101-108.

Catala, A. 2009. Lipid peroxidation of membrane phospholipids generates hydroxy-alkenals and oxidized phospholipids active in physiological and/or pathological conditions. Chem. Phys. Lipids $157: 1-11$

Chiang, C. Y., V. Veckman, K. Limmer, and M. David. 2012. Phospholipase Cgamma-2 and intracellular calcium are required for lipopolysaccharide-induced Toll-like receptor 4 (TLR4) endocytosis and interferon regulatory factor 3 (IRF3) activation. J. Biol. Chem. 287:3704-3709.

Dougherty, R. M., C. Galli, A. Ferro-Luzzi, and J. M. Iacono. 1987. Lipid and phospholipid fatty acid composition of plasma, red blood cells, and platelets and how they are affected by dietary lipids: A study of normal subjects from Italy, Finland, and the USA. Am. J. Clin. Nutr. 45:443-455.

Duda, M. K., K. M. O'Shea, A. Tintinu, W. Xu, R. J. Khairallah, B. R. Barrows, D. J. Chess, A. M. Azimzadeh, W. S. Harris, V. G. Sharov, H. N. Sabbah, and W. C. Stanley. 2009. Fish oil, but not flaxseed oil, decreases inflammation and prevents pressure overload-induced cardiac dysfunction. Cardiovasc. Res. 81:319-327.

Eberhart, R. J. 1977. Coliform mastitis. J. Am. Vet. Med. Assoc. 170:1160-1163.

Emken, E. A., R. O. Adlof, and R. M. Gulley. 1994. Dietary linoleic acid influences desaturation and acylation of deuterium-labeled linoleic and linolenic acids in young adult males. Biochim. Biophys. Acta 1213:277-288.
Ereso, A. Q., E. L. Cureton, M. W. Cripps, J. Sadjadi, M. M. Dua, B. Curran, and G. P. Victorino. 2009. Lipoxin a(4) attenuates microvascular fluid leak during inflammation. J. Surg. Res. 156:183-188.

Glasser, F., P. Schmidely, D. Sauvant, and M. Doreau. 2008. Digestion of fatty acids in ruminants: A meta-analysis of flows and variation factors: 2. C18 fatty acids. Animal 2:691-704.

Guido, D. M., R. McKenna, and W. R. Mathews. 1993. Quantitation of hydroperoxy-eicosatetraenoic acids and hydroxy-eicosatetraenoic acids as indicators of lipid peroxidation using gas chromatography-mass spectrometry. Anal. Biochem. 209:123-129.

Guillou, H., D. Zadravec, P. G. Martin, and A. Jacobsson. 2010. The key roles of elongases and desaturases in mammalian fatty acid metabolism: Insights from transgenic mice. Prog. Lipid Res. 49:186-199.

Haghiac, M., X. H. Yang, L. Presley, S. Smith, S. Dettelback, J. Minium, M. A. Belury, P. M. Catalano, and S. Hauguel-de Mouzon. 2015. Dietary omega-3 fatty acid supplementation reduces inflammation in obese pregnant women: A randomized double-blind controlled clinical trial. PLoS One 10:e0137309.

Itoh, T. L. Fairall, K. Amin, Y. Inaba, A. Szanto, B. L. Balint, L. Nagy, K. Yamamoto, and J. W. Schwabe. 2008. Structural basis for the activation of PPARgamma by oxidized fatty acids. Nat. Struct. Mol. Biol. 15:924-931.

Jenkins, T. C., R. J. Wallace, P. J. Moate, and E. E. Mosley. 2008. Board-invited review: Recent advances in biohydrogenation of unsaturated fatty acids within the rumen microbial ecosystem. J. Anim. Sci. 86:397-412.

Kronke, G., J. Katzenbeisser, S. Uderhardt, M. M. Zaiss, C. Scholtysek, G. Schabbauer, A. Zarbock, M. I. Koenders, R. Axmann, J. Zwerina, H. W. Baenckler, W. van den Berg, R. E. Voll, H. Kuhn, L. A. Joosten, and G. Schett. 2009. 12/15-lipoxygenase counteracts inflammation and tissue damage in arthritis. J. Immunol 183:3383-3389.

Lands, W. E., M. Inoue, Y. Sugiura, and H. Okuyama. 1982. Selective incorporation of polyunsaturated fatty acids into phosphatidylcholine by rat liver microsomes. J. Biol. Chem. 257:14968-14972.

Leigh, J. A., S. A. Egan, P. N. Ward, T. R. Field, and T. J. Coffey. 2010. Sortase anchored proteins of Streptococcus uberis play major roles in the pathogenesis of bovine mastitis in dairy cattle. Vet. Res. 41:63.

Lock, A. L., C. L. Preseault, J. E. Rico, K. E. DeLand, and M. S. Allen. 2013. Feeding a C16:0-enriched fat supplement increased the yield of milk fat and improved conversion of feed to milk. J. Dairy Sci. 96:6650-6659.

Lock, A. L., C. Tyburczy, D. A. Dwyer, K. J. Harvatine, F. Destaillats, Z. Mouloungui, L. Candy, and D. E. Bauman. 2007. Trans-10 octadecenoic acid does not reduce milk fat synthesis in dairy cows. J. Nutr. 137:71-76.

Marcel, Y. L., K. Christiansen, and R. T. Holman. 1968. The preferred metabolic pathway from linoleic acid to arachidonic acid in vitro. Biochim. Biophys. Acta 164:25-34.

Mattmiller, S. A., B. A. Carlson, J. C. Gandy, and L. M. Sordillo. 2014. Reduced macrophage selenoprotein expression alters oxidized lipid metabolite biosynthesis from arachidonic and linoleic acid. J. Nutr. Biochem. 25:647-654.

Mavangira, V., J. C. Gandy, C. Zhang, V. E. Ryman, A. D. Jones, and L. M. Sordillo. 2015. Polyunsaturated fatty acids influence differential biosynthesis of oxylipids and other lipid mediators during bovine coliform mastitis. J. Dairy Sci. 98:6202-6215.

Min, Y., O. Djahanbakhch, J. Hutchinson, A. S. Bhullar, M. Raveendran, A. Hallot, S. Eram, I. Namugere, S. Nateghian, and K. Ghebremeskel. 2014. Effect of docosahexaenoic acid-enriched fish oil supplementation in pregnant women with Type 2 diabetes on membrane fatty acids and fetal body composition-double-blinded randomized placebo-controlled trial. Diabet. Med. 31:1331-1340.

Moyes, K. M., T. Larsen, P. Sorensen, and K. L. Ingvartsen. 2014. Changes in various metabolic parameters in blood and milk during experimental Escherichia coli mastitis for primiparous Holstein dairy cows during early lactation. J. Anim. Sci. Biotechnol. 5:47. 
Nagy, L., P. Tontonoz, J. G. Alvarez, H. Chen, and R. M. Evans. 1998. Oxidized LDL regulates macrophage gene expression through ligand activation of PPARgamma. Cell 93:229-240.

Nakamura, M. T., and T. Y. Nara. 2003. Essential fatty acid synthesis and its regulation in mammals. Prostaglandins Leukot. Essent. Fatty Acids 68:145-150.

Oliver, S. P., R. A. Almeida, and L. F. Calvinho. 1998. Virulence factors of Streptococcus uberis isolated from cows with mastitis. Zentralbl. Veterinarmed. B. 45:461-471.

Patterson, E., R. Wall, G. F. Fitzgerald, R. P. Ross, and C. Stanton. 2012. Health implications of high dietary omega-6 polyunsaturated fatty acids. J. Nutr. Metab. 2012:539426.

Pedersen, L. H., B. Aalbaek, C. M. Rontved, K. L. Ingvartsen, N. S Sorensen, P. M. Heegaard, and H. E. Jensen. 2003. Early pathogenesis and inflammatory response in experimental bovine mastitis due to Streptococcus uberis. J. Comp. Pathol. 128:156-164.

Petit, H. V., R. J. Dewhurst, N. D. Scollan, J. G. Proulx, M. Khalid, W. Haresign, H. Twagiramungu, and G. E. Mann. 2002. Milk production and composition, ovarian function, and prostaglandin secretion of dairy cows fed omega-3 fats. J. Dairy Sci. 85:889-899.

Poulsen, R. C., K. H. Gotlinger, C. N. Serhan, and M. C. Kruger. 2008. Identification of inflammatory and proresolving lipid mediators in bone marrow and their lipidomic profiles with ovariectomy and omega-3 intake. Am. J. Hematol. 83:437-445.

Ramsden, C. E., A. Ringel, A. E. Feldstein, A. Y. Taha, B. A. MacIntosh, J. R. Hibbeln, S. F. Majchrzak-Hong, K. R. Faurot, S. I. Rapoport, Y. Cheon, Y. M. Chung, M. Berk, and J. D. Mann. 2012. Lowering dietary linoleic acid reduces bioactive oxidized linoleic acid metabolites in humans. Prostaglandins Leukot. Essent. Fatty Acids 87:135-141.

Raphael, W., and L. M. Sordillo. 2013. Dietary polyunsaturated fatty acids and inflammation: The role of phospholipid biosynthesis. Int. J. Mol. Sci. 14:21167-21188.

Røntved, C. M., J. B. Andersen, J. Dernfalk, and K. L. Ingvartsen 2005. Effects of diet energy density and milking frequency in early lactation on tumor necrosis factor-alpha responsiveness in dairy cows. Vet. Immunol. Immunopathol. 104:171-181.

Ryman, V. E., G. M. Pighetti, J. D. Lippolis, J. C. Gandy, C. M Applegate, and L. M. Sordillo. 2015. Quantification of bovine oxylipids during intramammary Streptococcus uberis infection. Prostaglandins Other Lipid Mediat. 121:207-217.

Schmelzer, K. R., L. Kubala, J. W. Newman, I. H. Kim, J. P. Eiserich, and B. D. Hammock. 2005. Soluble epoxide hydrolase is a therapeutic target for acute inflammation. Proc. Natl. Acad. Sci. USA 102:9772-9777.

Schuchardt, J. P., I. Schneider, I. Willenberg, J. Yang, B. D. Hammock, A. Hahn, and N. H. Schebb. 2014. Increase of EPA-derived hydroxy, epoxy and dihydroxy fatty acid levels in human plasma after a single dose of long-chain omega-3 PUFA. Prostaglandins Other Lipid Mediat. 109-111:23-31.

Sellers, M. D., L. E. Hulbert, and M. A. Ballou. 2013. Technical note: Determination of preanalysis storage temperature and time allowances for ex vivo innate immune responses. J. Dairy Sci. 96:384389

Serhan, C. N. 1994. Lipoxin biosynthesis and its impact in inflammatory and vascular events. Biochim. Biophys. Acta 1212:1-25.
Serhan, C. N., and N. A. Petasis. 2011. Resolvins and protectins in inflammation resolution. Chem. Rev. 111:5922-5943.

Shiraki, T., N. Kamiya, S. Shiki, T. S. Kodama, A. Kakizuka, and H. Jingami. 2005. Alpha,beta-unsaturated ketone is a core moiety of natural ligands for covalent binding to peroxisome proliferatoractivated receptor gamma. J. Biol. Chem. 280:14145-14153.

Silva, L. P., P. L. Lorenzi, P. Purwaha, V. Yong, D. H. Hawke, and J. N. Weinstein. 2013. Measurement of DNA concentration as a normalization strategy for metabolomic data from adherent cell lines. Anal. Chem. 85:9536-9542.

Sinclair, A. J., N. M. Attar-Bashi, and D. Li. 2002. What is the role of alpha-linolenic acid for mammals? Lipids 37:1113-1123.

Smith, W. L., Y. Urade, and P. J. Jakobsson. 2011. Enzymes of the cyclooxygenase pathways of prostanoid biosynthesis. Chem. Rev. 111:5821-5865.

Snyder, N. W., F. Golin-Bisello, Y. Gao, I. A. Blair, B. A. Freeman, and S. G. Wendell. 2015. 15-Oxoeicosatetraenoic acid is a 15-hydroxyprostaglandin dehydrogenase-derived electrophilic mediator of inflammatory signaling pathways. Chem. Biol. Interact. 234:144-153.

Sordillo, L. M., J. A. Weaver, Y. Z. Cao, C. Corl, M. J. Sylte, and I. K. Mullarky. 2005. Enhanced 15-HPETE production during oxidant stress induces apoptosis of endothelial cells. Prostaglandins Other Lipid Mediat. 76:19-34.

Strandberg, Y., C. Gray, T. Vuocolo, L. Donaldson, M. Broadway, and R. Tellam. 2005. Lipopolysaccharide and lipoteichoic acid induce different innate immune responses in bovine mammary epithelial cells. Cytokine 31:72-86.

Tam, V. C. 2013. Lipidomic profiling of bioactive lipids by mass spectrometry during microbial infections. Semin. Immunol. 25:240-248.

Thomas, L. H., W. Haider, A. W. Hill, and R. S. Cook. 1994. Pathologic findings of experimentally induced Streptococcus uberis infection in the mammary gland of cows. Am. J. Vet. Res. 55:17231728.

West, B. T., K. B. Welch, and A. T. Galecki. 2015. Linear Mixed Models: A Practical Guide Using Statistical Software. 2nd ed. Taylor \& Francis Group, Boca Raton, FL.

Wiesner, R., H. Suzuki, M. Walther, S. Yamamoto, and H. Kuhn 2003. Suicidal inactivation of the rabbit 15 -lipoxygenase by $15 \mathrm{~S}$ HpETE is paralleled by covalent modification of active site peptides. Free Radic. Biol. Med. 34:304-315.

Yao, H. T., Y. W. Chang, S. J. Lan, C. T. Chen, J. T. Hsu, and T. K. Yeh. 2006. The inhibitory effect of polyunsaturated fatty acids on human CYP enzymes. Life Sci. 79:2432-2440.

Zhao, X., T. Yamamoto, J. W. Newman, I. H. Kim, T. Watanabe, B. D. Hammock, J. Stewart, J. S. Pollock, D. M. Pollock, and J. D. Imig. 2004. Soluble epoxide hydrolase inhibition protects the kidney from hypertension-induced damage. J. Am. Soc. Nephrol. 15:1244-1253.

Zu, L., J. He, H. Jiang, C. Xu, S. Pu, and G. Xu. 2009. Bacterial endotoxin stimulates adipose lipolysis via toll-like receptor 4 and extracellular signal-regulated kinase pathway. J. Biol. Chem. 284:5915-5926. 


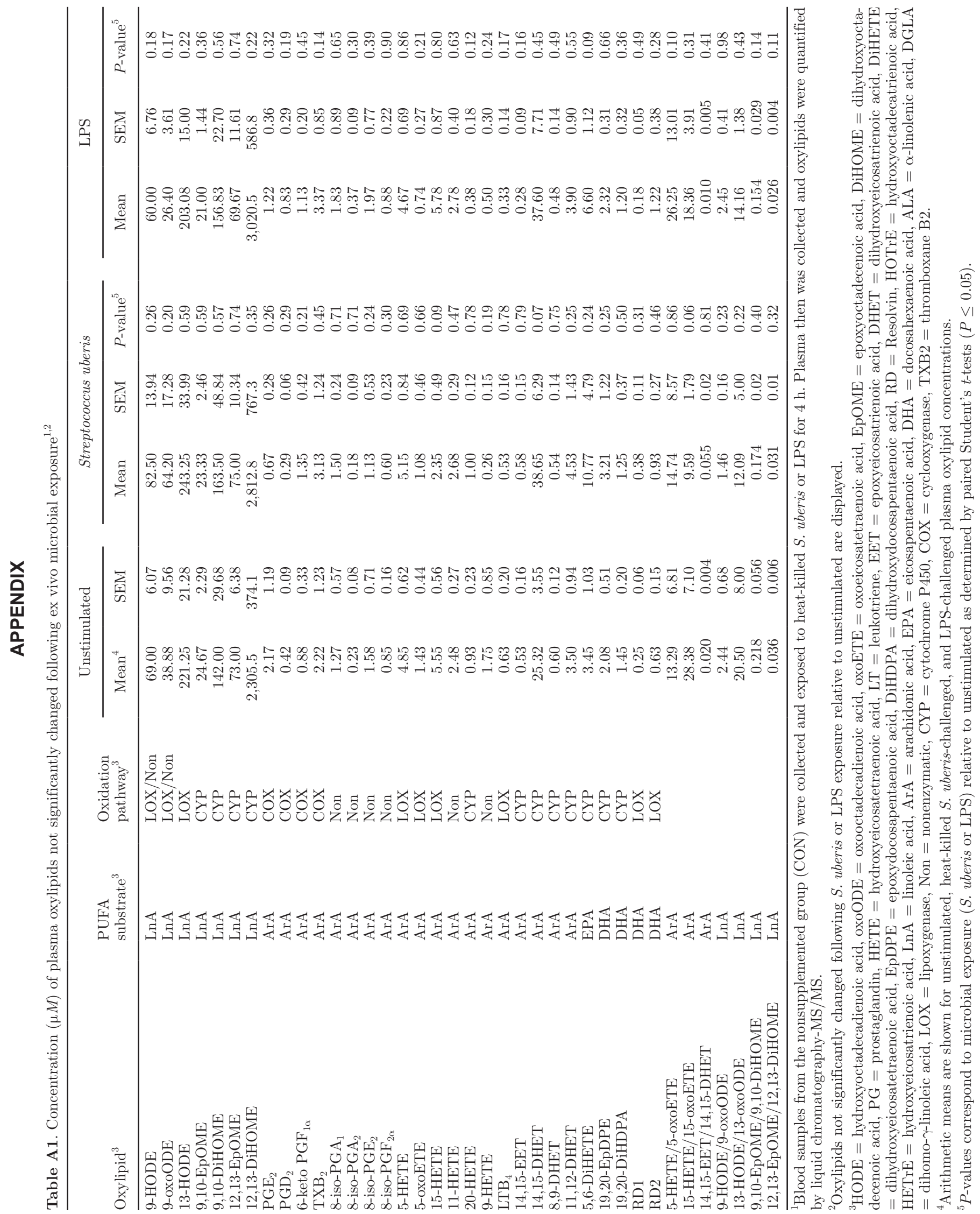




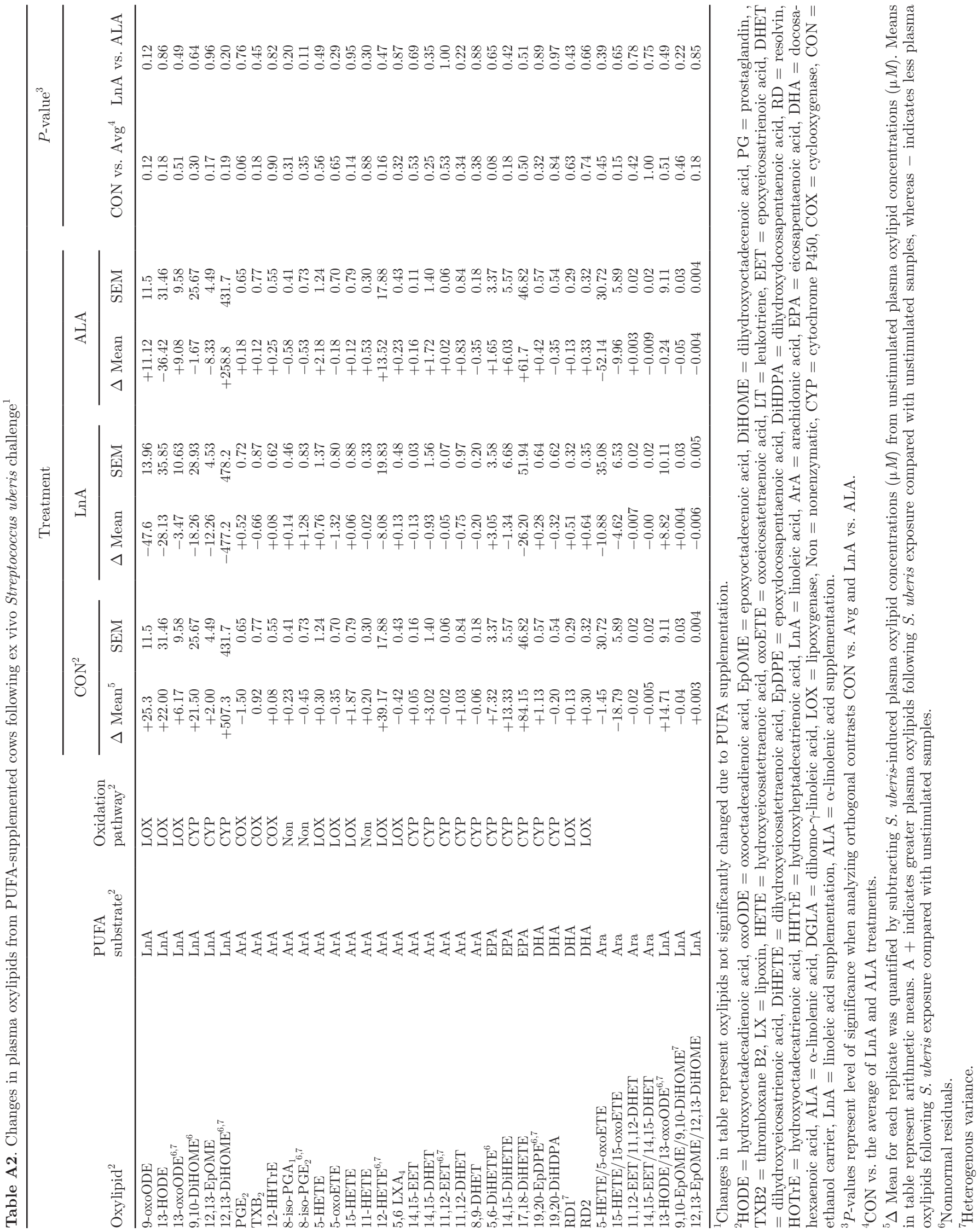




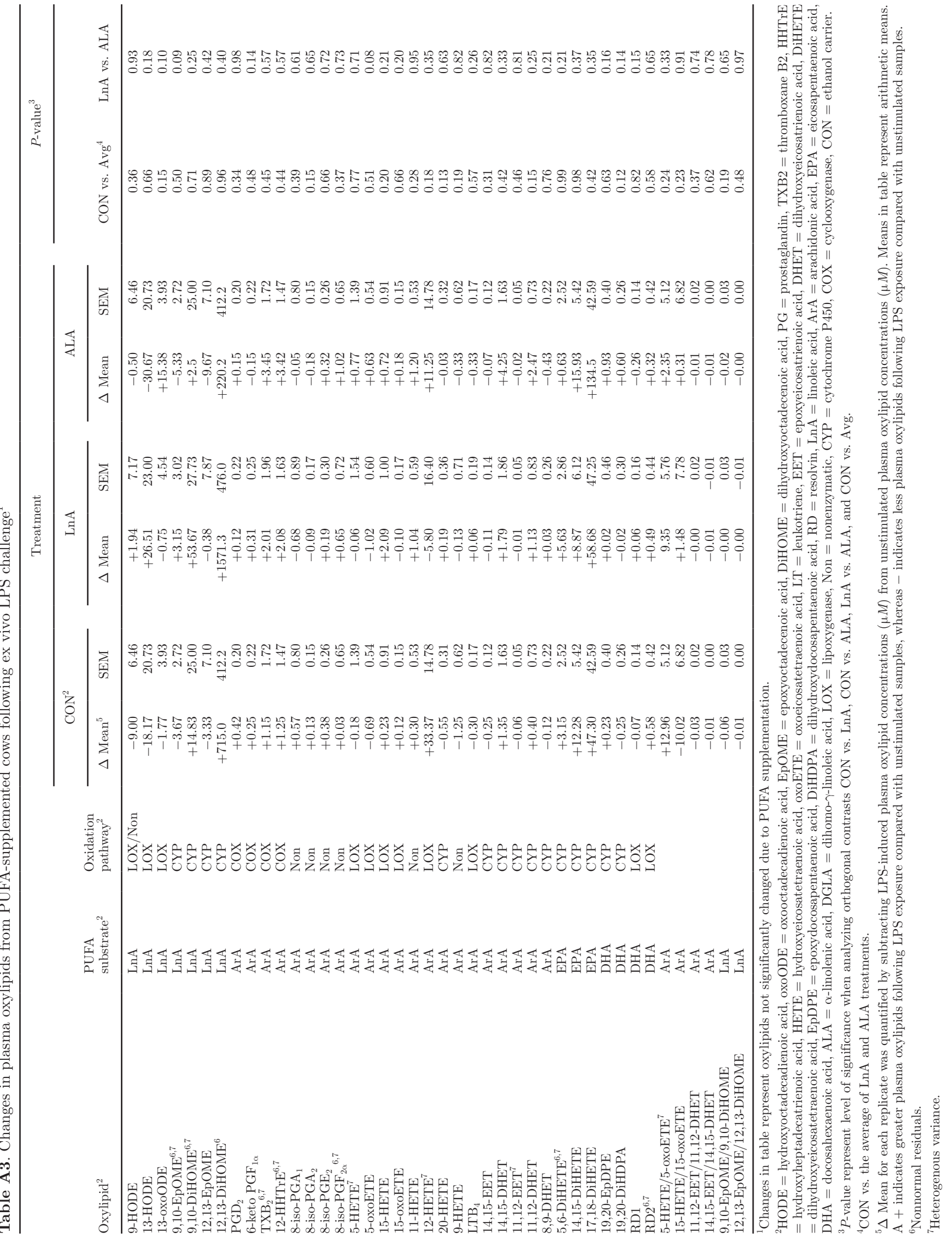

